\title{
The Role of Human Resources Information Systems in Enforcing Knowledge Management: A field study - the Ministry of Transport in Gaza Strip
}

Esmail A. M. Kassim*

The Islamic University of Gaza,

Gaza Strip, Palestine.

Email: eqasem@iugaza.edu.ps

\author{
Allaa Khalil El Ukosh \\ Ministry of Transport, \\ Gaza, Palestine. \\ Email: allaa.ukosh@hotmail.com
}

Received July, 2020; Accepted September, 2020

\begin{abstract}
The study examined the Human Resource Information System's features (training information systems, performance appraisal information systems, employment information systems, incentive information systems, HRIS information systems) in the Ministry of Transport in the Gaza Strip. It measured their effects on knowledge management dimensions (knowledge generation, knowledge storage, knowledge dissemination, knowledge application). The researchers used the descriptive-analytical method. The study population consisted of all employees in supervisory positions in the Ministry of Transport. The questionnaire was used to collect the required data. The number of respondents was 62 respondents with a recovery rate $(82.3 \%)$. Data was analyzed using SPSS statistical program. The study showed that there is a statistically significant relationship between the application level of human resources information systems and knowledge management application in the Ministry of Transport. In addition, the application level of human resources information systems impacts the application level of knowledge management at a rate of (\%83.40).
\end{abstract}

Keywords: Human Resources; Information Systems; Knowledge Management; Palestine.

Type: Research paper

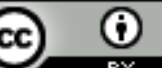

BY This work is licensed under a Creative Commons Attribution 4.0 International License.

DOI: 10.51325/ijbeg.v3i3.48

$$
\begin{aligned}
& \text { عنوان الدراسة: دور نظم معلومات الموارد البشرية في تعزيز ادارة المعرفة } \\
& \text { (دراسة ميدانية - ونارة النقل والمواصلات بقطاع غزة) }
\end{aligned}
$$

هدفت الدراسة إلى معرفة دور نظم معلومات الموارد البشرية بأبعادها (نظم معلومات التدريب، نظم معلومات تقييم

الأداء، نظم معلومـات التوظيف، نظم معلومات الحوافز، نظم تخطيط معلومات الموارد البشرية) في تعزيز ادارة

المعرفة بأبعادها (توليد المعرفة، تخزين المعرفة، نشر المعرفة، تطبيق المعرفة) بوزارة النقل والمواصـلات بقطاع

غزة، وقد استخدم الباحثون المـهـج الوصفي التحليلي، وتكـون مجتمع الدراسـة مـن جميع العـاملين في الوظـائف الإشرافية في الوزارة، وكانت الاستبانة أداة جمع البيانات، وتم تطبيق أسلوب المسح الثامل، وبلغت عدد المبحوثين (62)، وكانـت نسبة الاسترداد (82.3\%)، وحللت البيانـات باستخدام برنـامج SPSS الاحصـائي، وكان من أهم النتائج وجود علاقة ذات دلالة إحصـائية بين واقع تطبيق نظم معلومات الموارد البشرية وبين مستوى تطبيق إدارة 
المعرفة في الوزارة، واتضح وجود أثر ذو دلالة إحصائية بين واقع تطبيق نظم معلومات الموارد البشرية وبين مستوى تطبيق إدارة المعرفة بنسبة (83.40\%) في الوزارة. الكلمات المفتاحية: نظم معلومات، الموارد البشرية، ادارة المعرفة، فلسطين. مقدمة الدراسة يعد الاهمام بتطوير المعرفة نحو التغيير الممنهج من أهم أدوات تطوير الخدمات والمنتجات بما يناسب توقعات الجمهور في ظل بيئة عالمية معاصرة متسارعة في التحديات وحدة المنافسة بين المؤسسات، وذلك نتيجة التغيير بوسائل ومفاهيم الإنتاج، وكذلك أساليب التكنولوجيا المستخدمة في تقديم الخدمات، والانتقال من مستوى المنافسة بالسوق المحلي والإقليمي للسوق العالمي، وأيضاً النمو الكبير في استخدام الوسائل والأدوات التكنولوجية والتسويق ولاتيق الاككتروني والاقتصاد الرقمي، الذي أوجب ضرورة لتمكين الموظفين والعاملين لمواجهة تلك التحديات (الحداد،

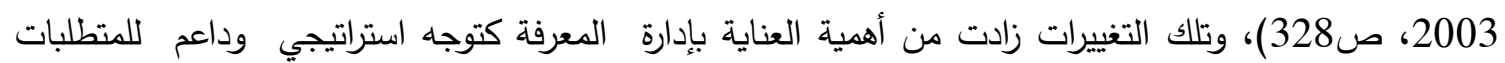
الأساسية في التطوير، والتي تعمل على تتمية قدرات العاملين وتثجعهم على استخدام أفضل التقنيات التكنولوجية،

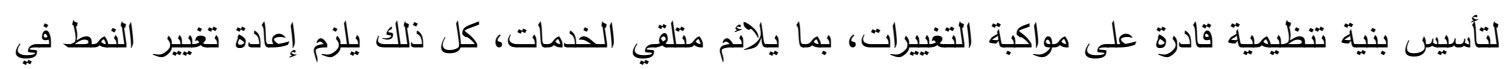
وسائل وتطبيقات الإدارة، (جاد الرب، 2008، صأسية 13)، وضرورة أن تمتلك منظمات الأعمال نظم موارد بشرية فاعلة، ومن موظفي ذوي ذكاء ومهارات عالية، باعتبارها عقول وأصول أساسية لدعم جهود عمليات ادارة المعرفة

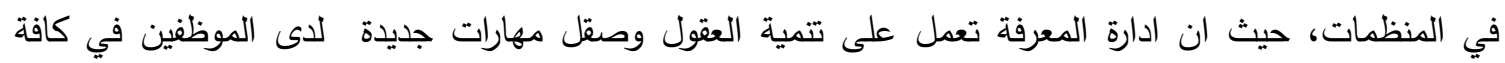
المستويات الادارية، لذلك تهتم الوزارة محل الدراسة بإعداد خطط لنشر المعرفة لتكون أكثر قدرة على خدمة أهدافها، ولكن هل يمكن أن يكون للاهتمام بتطوير نظم معلومات الموارد البشرية أثراً ايجابياً في تعزيز استراتيجية ادارة

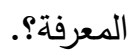

مشكلة الدراسة: تواجه وزارة النقل والمواصلات بغزة تحديات كبيرة وذلك لحساسية خدماتها، حيث أظهرت الاحصاءات والتقارير الصادرة عن نتائج عملها للسنوات (2017، 2018، 2019) مؤشرات حرجة عن تدني حجم خدماتها بمتوسط تقديري بنحو (40\%)، (تقارير الوزارة الصادرة 2017، 2018، 2019)، كذلك انخفاض كبير في العاملين في القطاع التجاري للنقل وأهمه تجارة المركبات وقطع الغيار وآلاف العاملين في قطاع النقل العمومي وقطاع الصيد

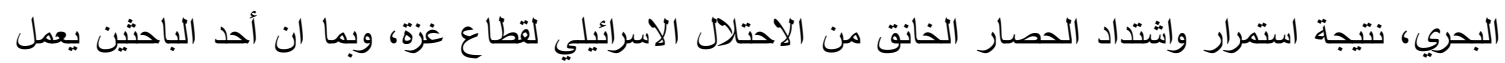

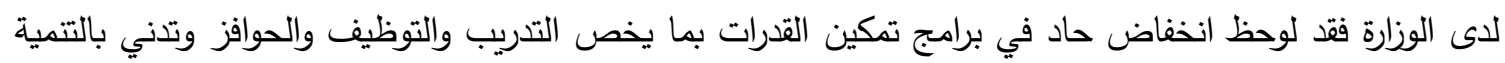
الادارية من خلال توقف برامج الابتعاث وتبادل الخبرات مع دول الجوار، مما أدى لانخفاض في مجهودات نشر لثرات

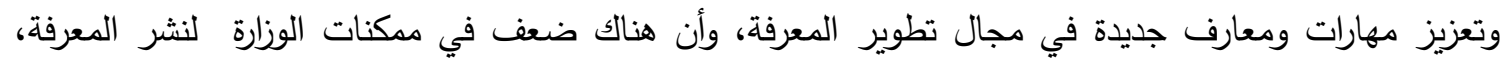
حيث تقدم الوزارة خدماتها لما يزيد عن (2 مليون) فلسطينيي كذلك يعمل نحو (17000) سائق في النقل العمومي، اضافة لنحو (4000) عامل في الصيد البحري، كذلك يعمل (3500) تاجر في تجارة قطع الغيار وبيع المركبات، وأيضاً التأثر السلبي لقطاع شركات التأمين التجاري، وتعطل عمل المعابر مما كبد اقتصاد النقل خسائر تجارية فادحة بقطاع غزة، وبناء عليه يرى الباحثون أنه من المكن أن يكون دور حيوي لإدارة ونشر المعرفة في وزارة النقل

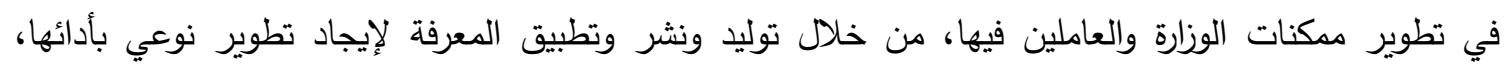
وكذلك التعرف على كيفية التغلب على المعوقات والتحديات التي قد تعيق احداث التطوير ونشر المعارف والمهارات لموظفي الوزارة، ولكن التحدي يكمن في كيف يمكن تفعيل ادارة المعرفة بالاعتماد على نظم معلومات موارد بشرية 
متكاملة ومتطورة وذات كفاءة، وبناء عليه يمكن طرح التساؤل التالي ما هو واقع نظم معلومات الموارد البشرية

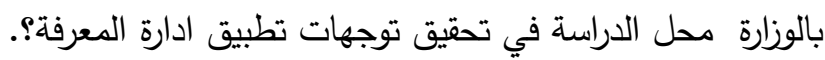
تساؤلات الاراسة: بناءً على عرض مشكلة الدراسة فإنه يمكن صياغة تساؤل الدراسة الرئيس كما يلي: السؤال الرئيس: - الكئ

ما دور نظم معلومات الموارد البشرية في تعزيز تطبيق إدارة المعرفة في وزارة النقل والمواصلات بقطاع غزة؟ ويتفرغ منه الأسئلة الفرعية التالية:

1. ما واقع تطبيق نظم معلومات الموارد البشرية في وزارة النقل والمواصلات بقطاع غزة؟

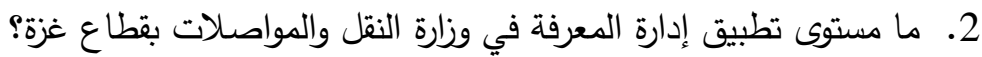

3. هل يوجد علاقة بين واقع تطبيق نظم معلومات الموارد البشرية وبين مستوى تطبيق إدارة المعرفة في وزارة

النقل والمواصلات بقطاع غزة؟

4. هل يوجد أثر بين واقع تطبيق نظم معلومات الموارد البشرية وبين مستوى تطبيق إدارة المعرفة في وزارة

النقل والمواصلات بقطاع غزة؟

5. هل يوجد فروق في استجابات أفراد عينة الدراسة حول واقع تطبيق نظم معلومات الموارد البشرية وحول مستوى تطبيق إدارة المعرفة في وزارة النقل والمواصلات بقطاع غزة تعزى لمتغيرات: (المسمى الوظيفي،

$$
\text { المؤهل العلمي، عدد سنوات الخدمة، الجنس)؟ بـ }
$$

فروض الاراسة

توجد علاقة ذات دلالة إحصائية بين نظم معلومات الموارد البشرية بأبعادها (نظم معلومات التدريب، نظم معلومات تقييم الأداء، نظم معلومات التوظيف، نظم معلومات الحوافز، نظم معلومات تخطيط المعلومات الموارد البشرية،) وتعزيز تطبيق ادارة المعرفة بأبعادها (توليد المعرفة، تخزين المعرفة، نشر وتوزيع المعرفة، تطبيق المعرفة) بوزارة النقل والمواصلات بغزة. ويمكن أن يتفرع منها الفروض التالية: 1. لا يوجد علاقة ذات دلالة إحصائية عند مستوى دلالة (150.05ه) بين واقع تطبيق نظم معلومات الموارد

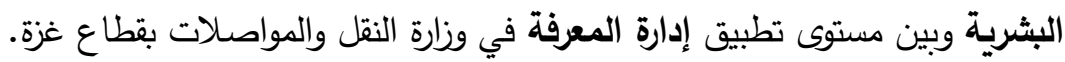

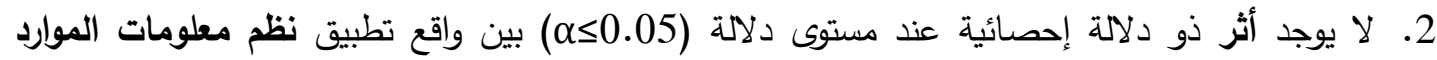

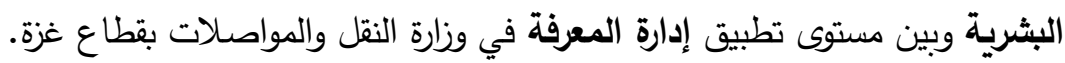

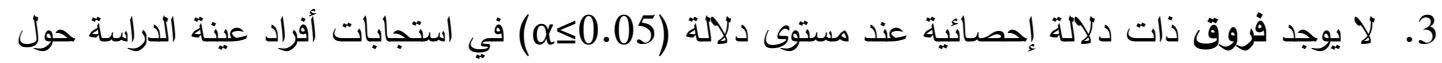
واقع تطبيق نظم معلومات الموارد البشرية وحول مستوى تطبيق إدارة المعرفة في وزارة النقل والمواصلات بقطاع غزة تعزى لمتغيرات: (المسمى الوظيفي، المؤهل العلمي، عدد سنوات الخدمة، الجنس).

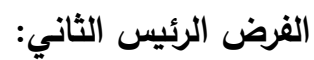
يوجد أثر ذو دلالة إحصائية عند مستوى دلالة $\alpha \leq 0.05$ بين استجابة المبحوثين حول مجالات نظم معلومات

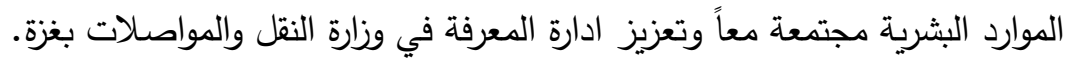

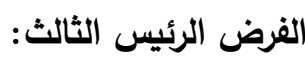

توجد فروق معنوية بين آراء المبحوثين حول بين نظم معلومات الموارد البشرية، وتعزيز ادارة المعرفة وفقًا للعوامل الديمغرافية (الجنس، المؤهل العلمي، سنوات الخبرة، المستوى الوظيفي). 
أهداف الاراسة:

1- التعرف على مدى توافر نظم معلومات الموارد البشرية متكاملة ومتطورة في وزارة النقل والمواصلات بغزة تعزز تطبيق ادارة المعرفة. 2- التعرف على مستوي توافر أبعاد ادارة المعرفة بين موظفين وزارة النقل والمواصلات بغزة.

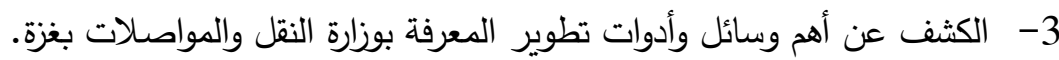

تسعى الدراسة للاطلاع على دور نظم معلومات الموارد البشرية وتقييم دورها في تعزيز ادارة المعرفة، ويمكن إبراز أهمية هذه الدراسة على النحو التالي:

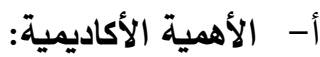

أظهرت الدراسات السابقة عدم كفاية الدراسات السابقة التي تتناولت نظم معلومات الموارد البشرية وربطها في ادارة

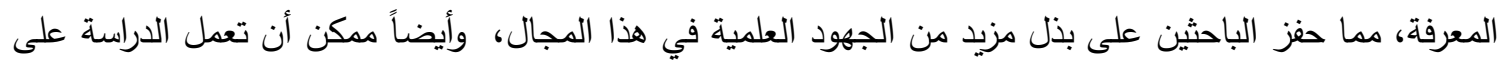

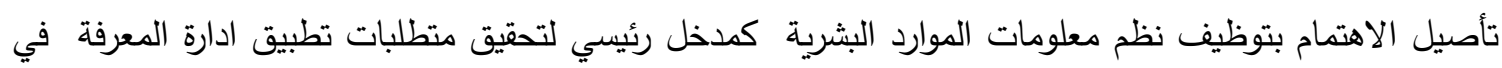

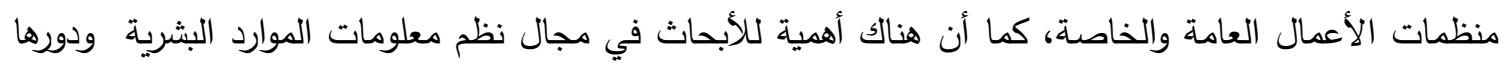
في ادارة المعرفة وذلك لأهميته الحيوية في تطوير قدرات المنظمات مما يتطلب توفير المزيد من الدراسات.

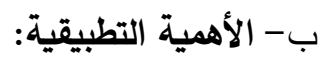

نفذت الدراسة على وزارة النقل والمواصلات بقطاع غزة والتي توصف بأنها من الوزارات الحيوية في الحكومة

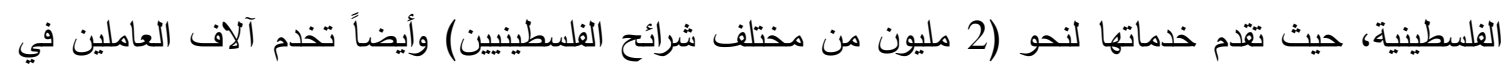
قطاع النقل البري والصيد البحري والتتقل، اضافة لدحاولة وضع حلول مبدعة لتعويض الخسارات الكبيرة في خدمات اقتصاد النقل، ويمكن الاستفادة من نتائج تحليل ادارة وبيئة عمل نظم معلومات الموارد البشرية في الوزارة لتعزيز ادارة المعرفة، كوسيلة رئيسية في التطوير والتتمية الادارية في الوزارة. ويمكن توضيح نقاط اضافية للأهمية التطبيقية للاراسة من خلال: - تحديد دور نظم معلومات الموارد البشرية في تعزيز دور نظم معلومات الموارد البشرية في ادارة المعرفة بوزارة النقل والمواصلات بغزة. قد تعد نتائج مثل هذه الدراسات أداة ومرجع للأجهزة المعنية في الدولة في متابعة وتطوير أداء المؤسسات. قد تساهم نتائج الدراسة في عرض الدور المفترض في تعزيز دور نظم معلومات الموارد البشرية في ادارة المعرفة.

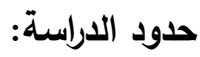
1- الحد المكاني: تم تطبيق الدراسة على وزارة النقل والمواصلات بقطاع غزة. 2- الحد البشري: تم تطبيق الدراسة على عينة من العاملين في مستويات وظائف الإدارة العليا والإدارة الإشرافية التتفيذية، من درجة وكيل وزارة ومدير عام حتى نائب رئيس شعبة.

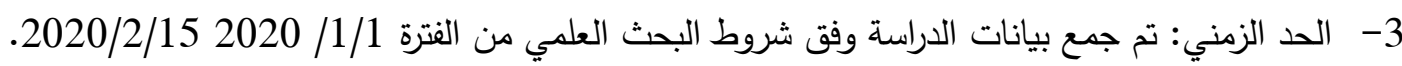
4- الحد الموضوعي: ركزت الدراسة على تقييم دور واقع نظم معلومات الموارد البشرية في تطبيق ادارة المعرفة وبأبعادها المتعددة. 
الإطار النظري

أولاً: مفهوم نظم معلومات الموارد البشرية: أدى التطور في التكنولوجيا المعاصرة إلى ثورة عالمية في التغيير بكافة قطاعات الصناعة، والتي كان لهات تأثير مباشر على تحول جذري في عمل ومهام منظمات الأعمال، كل ما سبق استوجب إحداث تغييرات تتظيمية تطويرية في تعزيز دور نظم معلومات الموارد البشرية لمواكبة التغييرات الراهنة في ظل انتثار ظاهرة المعرفة، والتغيير في

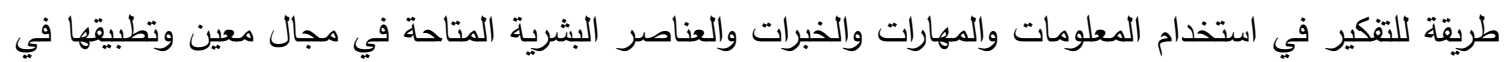

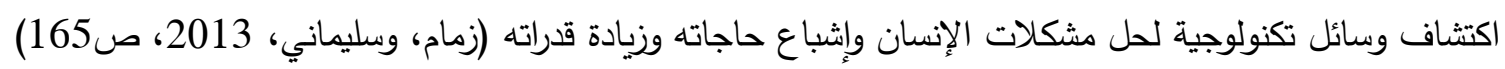
واعتبار أن التغييرات التكنولوجية مدخلاً للتغييرات التظظيمية في إعادة تصميم أنشطة ومهام المنظمة. (اللامي، 2007، ص ص 100- 101) كما يؤكد الطيطي (2011، ص ص ص 60-61) أن التغييرات في التقنيات التكنولوجيا وأنظمة المعلومات الإدارية أدت إلى ضرورة توفير متطلبات عمالية عالية المهارة والمعرفة في

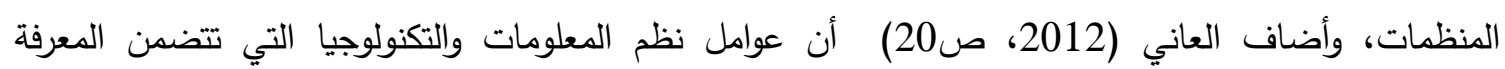
والاكتشاف الجديد وطرق الإبداع لمنتجات متميزة، كل ذلك يتوقف على حجم المعلومات لدى المنظمة لنجاح خطط

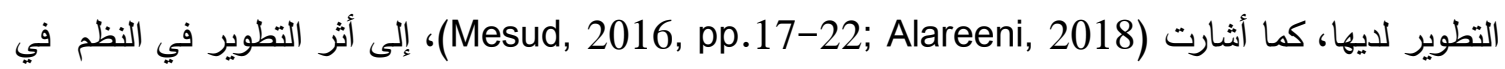

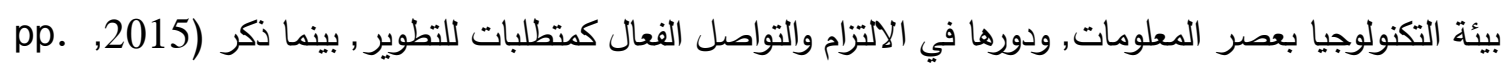
مده Kung'u

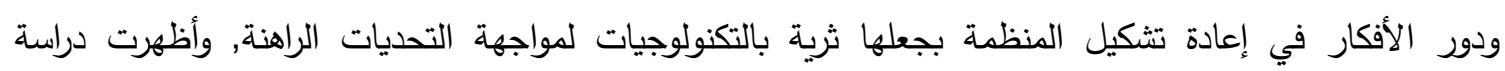
(Janjua, et al, 2013, pp. 83-93) البيئة الداخلية لمنظمات الأعمال، وتتطلب تغييرات في نظم إدارة الموارد البشرية التي تؤثر على احتياجات تتمية الكفاءات لفئة المديرين، في إعادة تصميم استراتيجيات التتمية. يستنبط الباحثون أن أنظمة معلومات الموارد البشرية الحديثة والمتكاملة مدكن أن تساهم بثكل أساسي في إنجاح

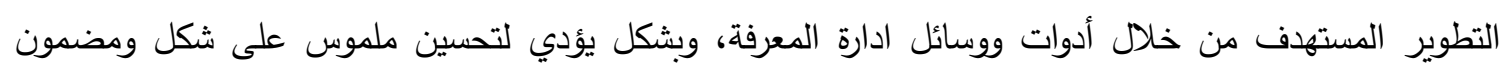

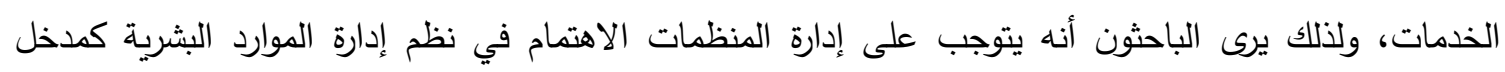
تطويري لإدارة المعرفة. أهمية نظم معلومات الموارد البثرية تعتبر نظم معلومات الموارد البشرية من أهم محاور نظم المعلومات الادارية في منظمات الأعمال بوصفها الرافد

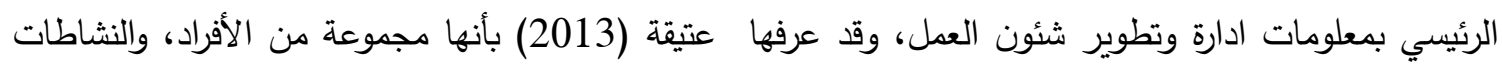
والأثكال، والبيانات تستعمل للحصول، تخزين، استرجاع وتوزيع، واستعمال المعلومات حول الموارد البشرية للمنظمة، كما يؤكد جاد الرب (2008، ص346 ) أن خطط التطوير للمؤسسات تتطلب توظيف الطاقات وبناء

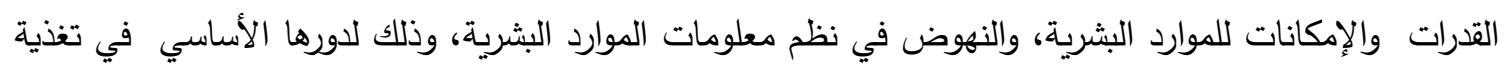

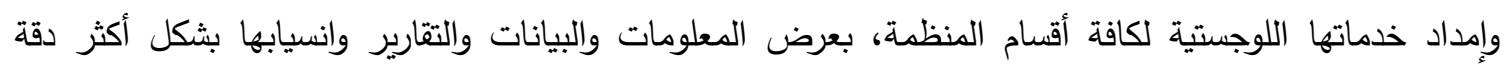

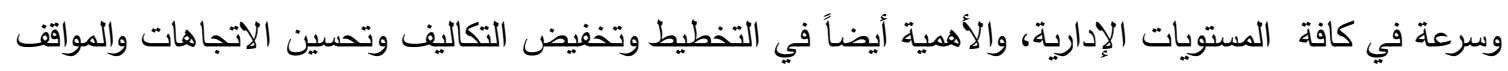
الوظيفية والتوجيه وبناء السياسات واتخاذ القرارات بمرونة وكفاءة، كما يرى أيوب (2001) أنه يتوجب على على الإدئ

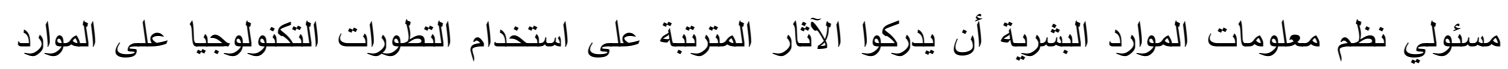

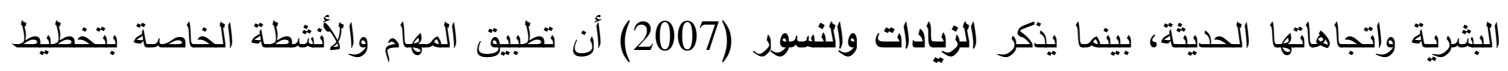

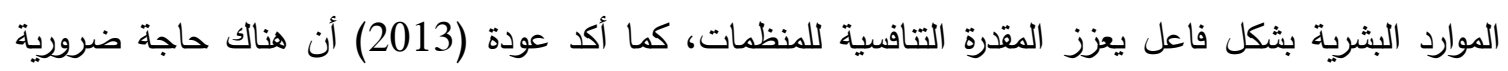


لزيادة دقة وسرعة وملائمة معلومات الموارد البشرية في مجالات أنظمة الحوافز والبرامج التدريبية، وأنظمة ولوائح

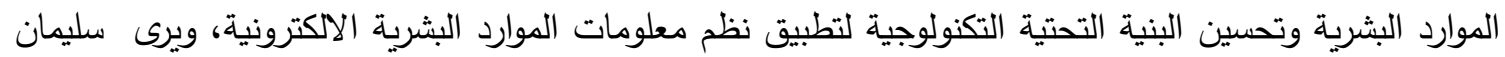
(2008) أن التدرج في إدخال التغيير وتكثيف التدريب وتبني أساليب الإبداع والتمكين، وإدارة الدعرفة واستخدام التقنيات الحديثة من أهم استراتيجيات التطوير، ويشير بن سماحة (2013) على أنه ئل يجب الاهتمام والعناية بمتطلبات المورد البشري والاهتمام بنظم الحوافز المادية والمعنوية وسياسات اختيار والتعيين والاهتمام بدورات

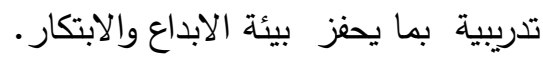
ويرى الباحثون بعد استعراض المفاهيم السابقة لنظم معلومات الموارد البشرية، أن نجاح المهام نظم الموارد البشرية المتعددة، وأهمها التخطيط والتدريب والتعيين والحوافز واعتبارها ركيزة أساسية في نمو وتقدم منظمات الأعمال، ويساهم في سرعة التحول في مواكبة التطوير ونشر ادارة المعرفة في منظمات الأعمال. ثانياً: ادارة المعرفة

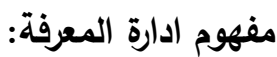
ازداد الاهتمام في ادارة المعرفة كمدخل استراتيجي في تطوير منظمات الأعمال العامة والخاصة والأهلية، وكان

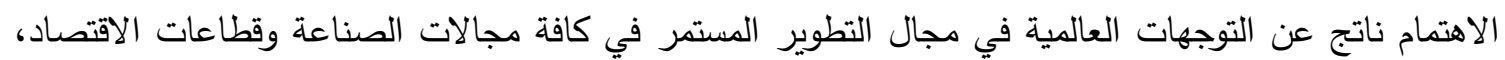

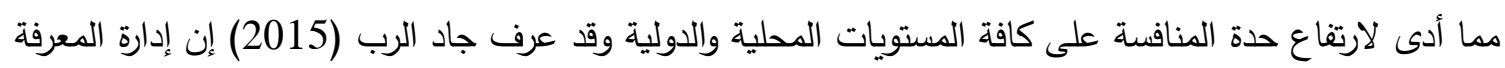

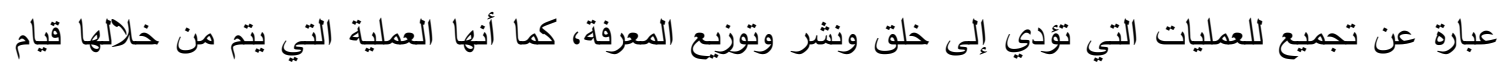

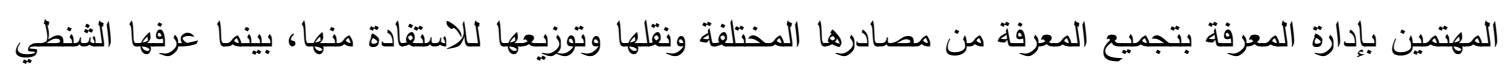
(2015) بأنها العمليات التي تعد حصيلة التجارب والخبرات والمعلومات النظرية والعملية التي ترتبط بشخصية الإنسان وارضيته الثقافية والعملية التي تؤدي إلى خلق ونشر وتوزيع المعرفة التي يتم من خلالها قيام المهتمين

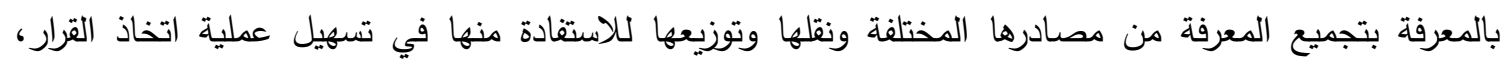
ويمكن أن يعكس مفهوم ادارة المعرفة كما ذكرها جاد الرب (2009) أنها تشمل كافة الأنشطة المهتمة بحصول المنظمة على المعرفة من الخبرات التي تمتلكها ومن الخبرات التي تعزز موقف المنظمة التكمه التنافسي. أهمية ادارة المعرفة

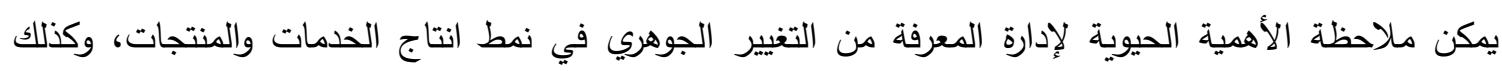
التحول الاستراتيجي في الميول الاستهلاكية على المستوى العالمي، خاصة بعد انتشار وسائل الاقتصاد الرقمي فئي

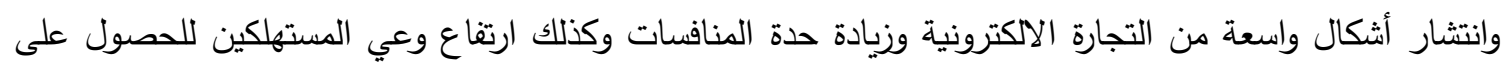

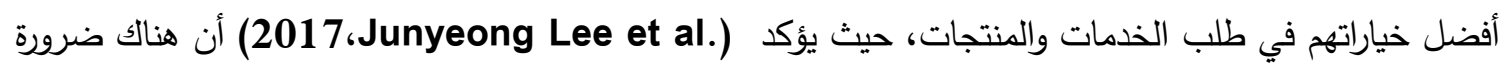
لتنظيم المعرفة و تعزيز مستوى الاتصال لزيادة فهم وتدفق المعرفة واكتسابها بين أعضاء الفريق في المنظمة ككل،

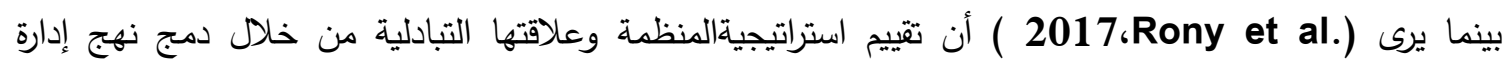

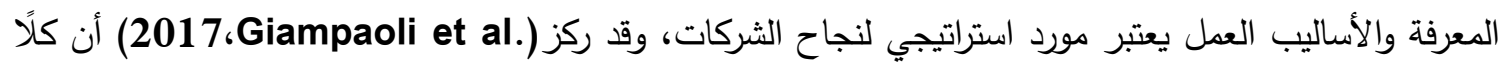
من المعرفة والإبداع عوامل هامة لحل المشاكل في من خلال وتبادل المعرفة وتعزيز قدرة المديرين الذين يواجهون

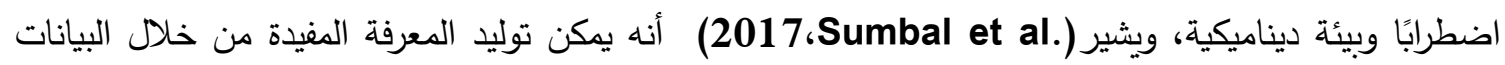

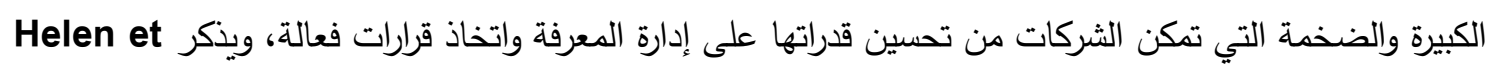
(2017،al) أساسا على نقل البيانات والمعلومات بالنسبة لنظم البيانات الكبيرة وتمكين العاملين على تقييم واتخاذ أفضل الفيل القرارات ونشر وتتسيق المعرفة وتطبيقها. 
ويستنتج الباحثون أن ادارة المعرفة تشمل مجموع من الخبرات والمعارف والتجارب المتراكمة في المنظمة والتي يجب أن تكون ادارة المنظمة قادرة على استغلالها في عمليات ادارة توليد وتطبيق وتخزين ونشر المعرفة بما يضيف ميزة تتافسية فريدة للمنظمة مقارنة بمجال عملها.

ثالثاً: الاراسات السابقة دراسة (بن قيراط، 2019)

هدفت هذه الدراسة إلى التعرف على مدى تأثير إدارة المعرفة على أداء الموارد البشرية ود ورها في تحسين مستواهم، حيث يعد أسلوب إدارة المعرفة في المؤسسات من أهم وأنجح الأساليب الإدارية الحديثة، ولذا حاولت هذه الداءئ الدراسة التعرف على وجهة نظر عمال مؤسسة اتصالات الجزائر لإدارة المعرفة ومساهتها في تحسين أدائهم، وتم استخدام

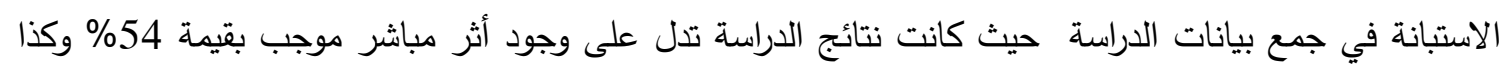
وجود أثر إيجابي غير مباشر من خلال تأثير المتغيرات الوسيطة وقبول التغيير التتظيمي، الرضا الوظيفي، وعلى التيل هذا الأساس تم تقديم مجموعة من الاقتراحات التي تدعم تطبيق إدارة المعرفة بمؤسسة اتصالات الجزائر وتساهم برفع مستوى أداء مواردها البشرية.

(Lendzion, 2015) دراسة موردون

تهدف الدراسة للتعرف على دور إدارة المعرفة في تطوير إدارة الموارد البشرية، وبناء القدرة التتافسية للشركة من

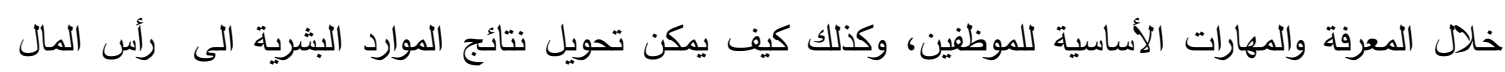

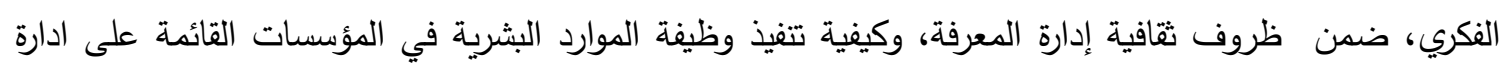

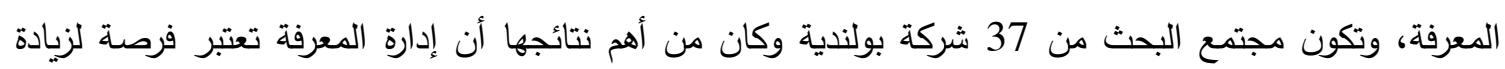

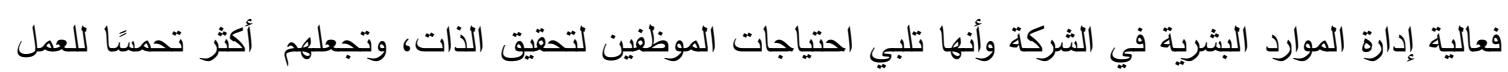

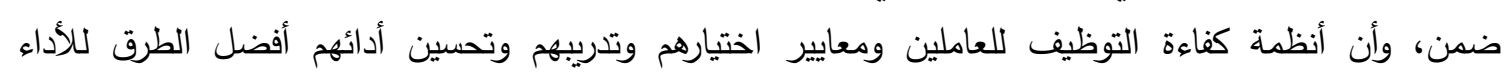
المطلوب.

(Fındıklı, \& Rofcanin, 2015 ) دراسة هدفت الدراسة الى محاولة معرفة آثار ممارسات الموارد البشرية الاستراتيجية على الابتكار التنظيمي (الاستكثاف

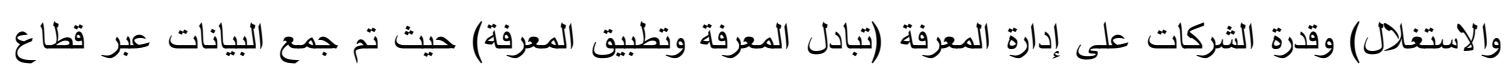
الصناعات العاملة في تركيا وبلغ عدد الشركات الخاضعة للدراسة 109 وكان من أهم نتائج الدراسة أن نتائج

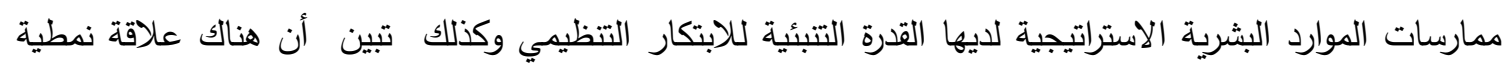

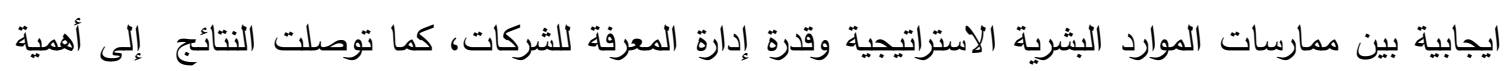
أنظمة التدريب وتقييم الأداء في تعزيز إدارة المعرفة والابتكار .

(Alageeli, Aalyateem, 2015 ) دراسة

هدفت الدراسة الى التعرف على دور ممارسات إدارة الموارد البشرية لدعم التعلم وادارة المعرفة في المنظمات، كما

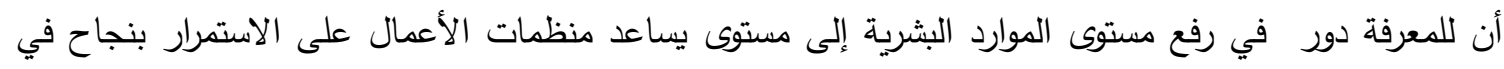

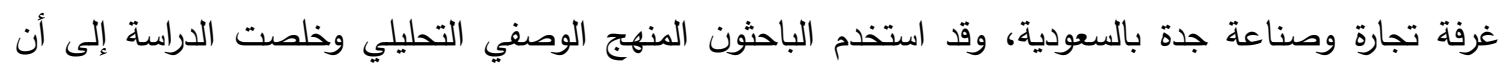
المعرفة يجب أن تركز على النواحي التطبيقية، وأن إدارة المعرفة تركز أولاً على الأفراد، والإجراءات التهات (العمليات)

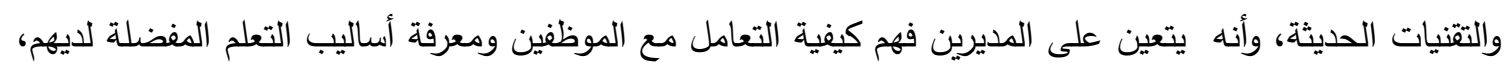


وضرورة التعرف على الدوافع التي تحثهم على العمل، وأنه يتعين على المسؤول التركيز على المعرفة ومشاركتها مع العاملين عند حل مشكلة معينة، أو حتى اتخاذ القرار مما يجعل المنظمة أكثر منافسة في أدائها.

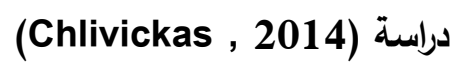

تهدف الدراسة الى محاولة السعي إلى حل المشكلات المعقدة للقطاع العام وذلك بالتركيز على زيادة فعالية هياكل الدولة، والاستفادة من التعاون الدولي وكذلك تحسين الكفاءة المهنية وموظفي الخدمة المدنية، لمعالجة بعض التباين بين الأولويات طويلة الأجل لتنمية الدولة وطرق تتفيذها، ووسائل تتمية نظم الموارد البشرية، من أجل إنشاء خدمة

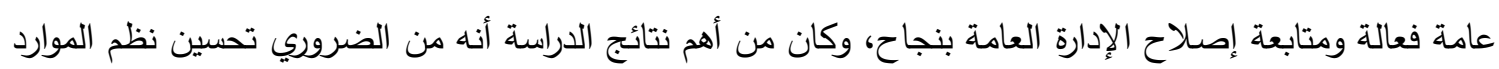
البشرية بثكل منهجي، من خلال الابتكارات لأن ذلك من شأنه أن يضمن النجاح في متابعة الأهداف والأولويات في إدارة الدولة وتحسين نظام الإدارة العامة في ليتوانيا. واستفاد الباحثون من تحليل الاراسات السابقة على النحو التالي:

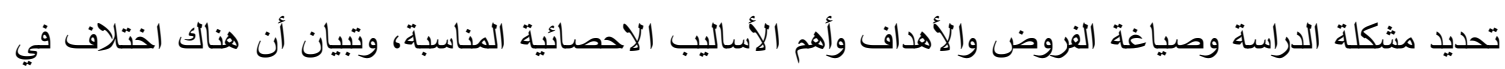

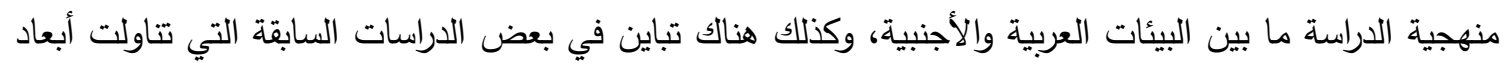

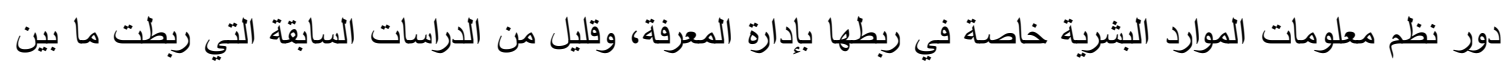
بعض أبعاد نظم معلومات الموارد البشرية وبعض أبعاد ادارة المعرفة لمنظمات الأعمال. منهجية الدراسة أولاً: منهج الداسنة اعتمدت الدراسة المنهج الوصفي التحليلي، الذي يفيد في فهم أفضل وأدق لجوانب وأبعاد الظاهرة موضوع الدراسة، حيث يصفها وصفاً دقيقاً، ويعبر عنها كيفياً وكمياً الوصفي التهان

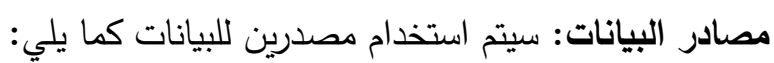
مصادر أولية: تم استخدام الاستبانة لجمع البيانات ذات الصلة لتحقيق أهداف الدراسة من خلال إعداد قائمة

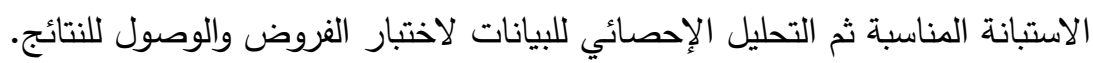
مصادر ثانوية: وذلك من خلال الاطلاع على الكتب والمراجع العربية والأجنبية ذات العلاقة، والدوريات والمقالات

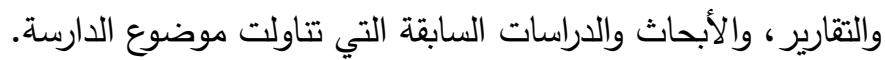
ثانياً: مجتمع الاراسة: يتكون مجتمع الدراسة من جميع العاملين في الوظائف الإشرافية في وزارة النقل والمواصلات بقطاع غزة، وعددهم (62) موظفاً. العينة الاستطلاعية: تكّونت عينة الدراسة الاستطلاعية من 30 مفردة، تم اختيارهم بطريقة عشوائية بغرض تقييم

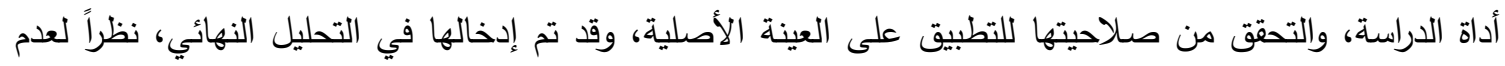

$$
\text { ثالثاً: عينة الدراسة: خلل الصدق والثبات. }
$$

تم استخدام أسلوب الحصر الثامل، نظرا لصغر حجم مجتمع الدراسة، حيث تم توزيع الاستبانات على جميع أفراد

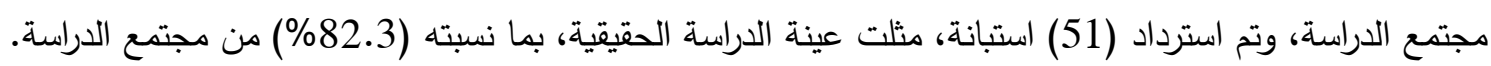
ويتوزع أفراد عينة الدراسة حسب الجدولة ولترداد الدالي: 
جدول رقم (1)

توزيع أفراد عينة الدراسة

\begin{tabular}{|c|c|c|c|}
\hline النسبة المئوية \% & العدد & الفئة & المسيى الوظيفي \\
\hline 11.8 & 6 & رئيس شعبة & \multirow{4}{*}{ المسيى الوظيفي } \\
\hline 25.5 & 13 & رئيس قسم & \\
\hline 47.1 & 24 & مدير دائرة & \\
\hline 15.7 & 8 & مدير عام & \\
\hline 21.6 & 11 & دبلوم متوسط & \multirow{3}{*}{ المؤهل العلمي } \\
\hline 58.8 & 30 & بكالوريوس & \\
\hline 19.6 & 10 & دراسات عليا & \\
\hline 9.8 & 5 & من 5-أقل من 10 سنوات & \multirow{3}{*}{ عدد سنوات الخدمة } \\
\hline 62.7 & 32 & من 10-أقل من 15 سنة & \\
\hline 27.5 & 14 & 15 سنة فأكثر & \\
\hline 88.2 & 45 & ذكر & \multirow{2}{*}{ الجنس } \\
\hline 11.8 & 6 & أنثى & \\
\hline$\% 100$ & 51 & المجموع & \\
\hline
\end{tabular}

رابعاً: أداة الدراسة: تم استخدام الاستبانة كأداة لجمع البيانات، وتتكون الاستبانة من مجموعة من المحاور والفقرات، تبين درجة الموافقة (كبيرة جدا، كبيرة، متوسطة، قليلة، قليلة جدا)، وتم تحديد القيم (5، 4، 3، 2، 1) لتقابل التقديرات السابقة لكل فقرة

$$
\text { من فقرات الاستبانة. }
$$

وتم حساب درجات الموافقة بحسب مقياس خماسي التدريج، كما هو مبين في الجدول التالي:

جدول رقم (2)

مقياس خماسي التدريج

\begin{tabular}{|c|c|c|c|c|}
\hline \multicolumn{2}{|c|}{ الوزن النسبي } & \multicolumn{2}{|c|}{ المتوسط الحسابي } & درجة \\
\hline إلى & 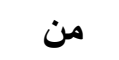 & إلى & من & الموافقة \\
\hline أقل من 36.00 & 20.00 & أقل من 1.80 & 1.00 & قليلة جدا \\
\hline أقل من 52.00 & 36.00 & أقل من 3.60 & 1.80 & قليلة \\
\hline أقل من 68.00 & 52.00 & أقل من 3.40 & 2.60 & متوسطة \\
\hline أقل من 84.00 & 68.00 & أقل من 4.20 & 3.40 & كبيرة \\
\hline 100.00 & 84.00 & 5.00 & 4.20 & كبيرة جدا \\
\hline
\end{tabular}


خامساً: صدق أداة الاراسة:

يعني صدق أداة الدراسـة أن الأداة تقيس مـا وضـعت لقياسـه، وتم التحقق من صدق الاستبانة من خـلال الطرق

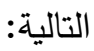

1. الصدق من وجهة المحكمين:

تم عرض الاستبانة على عدد (5) من المحكمين من ذوي الاختصاص، من أجل التأكد من سلامة الصياغة اللغوية

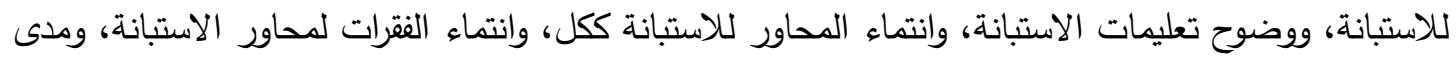

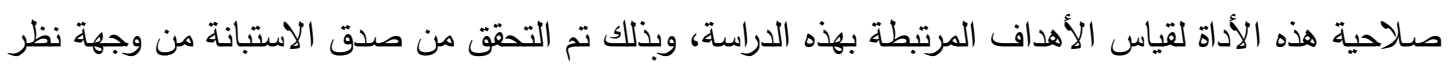
المحكمين. 2. - 2. صدق الاتساق الداخلي: تم حساب صدق الاتساق الداخلي من خلال إيجاد معاملات الارتباط لمحاور الاستبانة، وتراوحت ما بين (0.702)

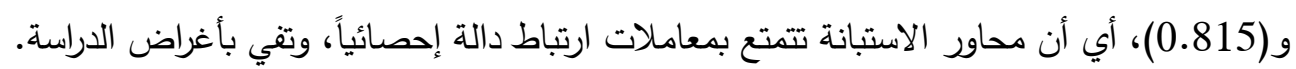

سادساً: ثبات أداة الاراسة: يعني ثبات أداة الدراسة أن الأداة تعطي نفس النتائج تقربباً لو طبقت مرة أخرى على نفس المجموعة من الأفراد، أي

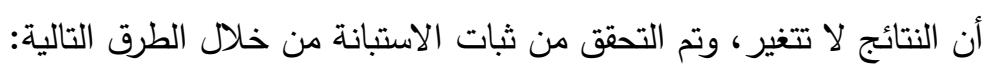

\section{1. الثبات باستخدام معادلة ألفا كرونباخ:}

تم التحقق من ثبات أداة الدراسة من خلال حساب معاملات الارتباط لمحاور الاستبانة باستخدام معادلة ألفا كرونباخ، وتراوحت ما بين (0.738) و(0.940)، أي أن معاملات الارتباط لمحاور الاستبانة باستخدام معادلة ألفا كرونباخ هي معاملات ثبات دالة إحصائياً، وتفي بأغراض الدراسة.

2. الثبات بطريقة التجزئة النصفية:

تم التحقق من ثبات أداة الدراسة من خلال حساب معاملات الارتباط لمحاور الاستبانة بطريقة التجزئة النصفية،

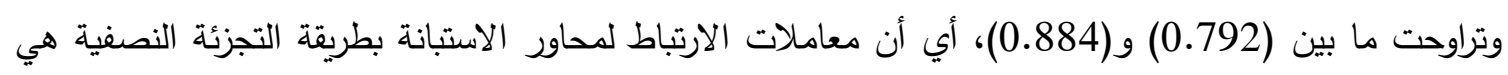
معاملات ثبات دالة إحصائياً، وتفي بأغراض الدراسة.

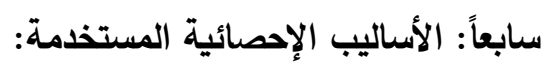
للإجابة على أسئلة الدراسة تم استخدام الرزمة الإحصائية للعلوم الاجتماعية (SPSS): (معامل ارتباط بيروسون،

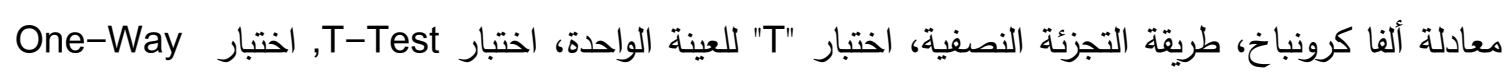
ANOVA للدراسة. وتم استخدام درجة ثقة (95\%) في اختبار كل الفروض الإحصائية للدراسة، بما يعني أن احتمال الخطأ يساوي (5) (5) وهي النسبة المناسبة لطبيعة الدراسة. ثامناً: اختبار توزيع البيانات:

تم استخدام اختبار كولمجوروف - سمرنوف Kolmogorov-Smirnov Test (K-S) لاختبار إذا كانت

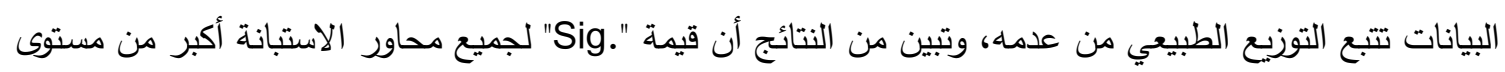
الدلالة (0.05)، وهذا يدل على أن جميع محاور الاستبانة تتبع التوزيع الطبيعي، أي أنه يمكن استخدام الاختبارات المعلمية. 
تاسعاً: نتائج الدراسة: نتائج السؤال الأول:

ينص السؤال على ما يلي: ما واقع تطبيق نظم معلومات الموارد البشرية في وزارة النقل والمواصلات بقطاع غزة؟ تم الإجابة على هذا السؤال باستخدام اختبار "T" للعينة الواحدة، كما هو مبين في الجدول لمات التالي:

جدول رقم (3)

تحليل بيانات محاور وفقرات نظم معلومات الموارد البشرية

\begin{tabular}{|c|c|c|c|c|c|c|c|c|}
\hline الموافقة & الترتيب & المزن & $\begin{array}{l}\text { قيمة } \\
\text { "Sig." }\end{array}$ & قيمة & الانحراف & المتوسط & الفقرة / المحور & s \\
\hline متوسطة & 2 & 63.529 & 0.241 & 1.186 & 2.124 & 6.353 & 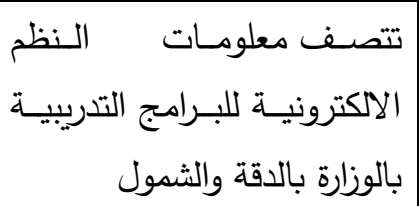 & 1 \\
\hline متوسطة & 4 & 59.804 & 0.953 & -0.059 & 2.371 & 5.980 & فاعلة للبرامج التدريبية بالوزارة & 2 \\
\hline متوسطة & 5 & 59.608 & 0.900 & -0.126 & 2.227 & 5.961 & 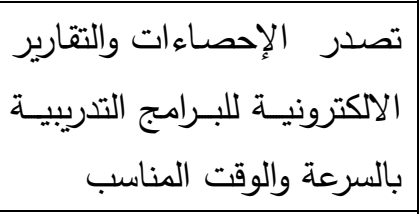 & 3 \\
\hline متوسطة & 3 & 63.137 & 0.316 & 1.012 & 2.214 & 6.314 & 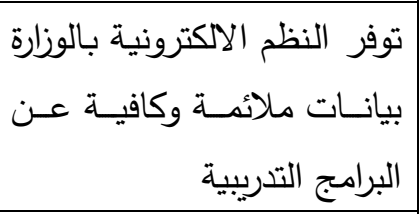 & 4 \\
\hline كبيرة & 1 & 72.353 & 0.000 & 5.667 & 1.557 & 7.235 & 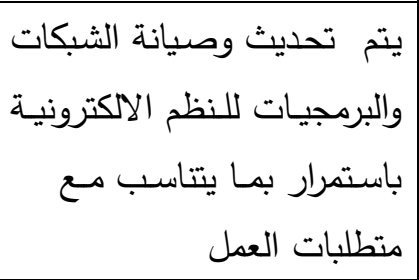 & 5 \\
\hline متوسطة & & 63.68 & 0.152 & 1.455 & 1.809 & 6.369 & نظم معلومات التدريب & \\
\hline كبيرة & 1 & 68.235 & 0.001 & 3.402 & 1.729 & 6.824 & تحرص الوزارة دائماً على الأداء الاككترونير نــاذج وتقـارير تقيـيم & 6 \\
\hline متوسطة & 2 & 66.078 & 0.029 & 2.250 & 1.930 & 6.608 & 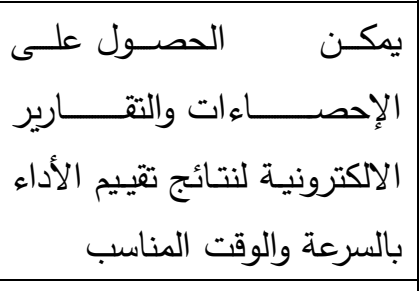 & 7 \\
\hline متوسطة & 4 & 63.333 & 0.175 & 1.377 & 1.728 & 6.333 & معلومـات ملائكـة وكافيـة تقدـم الاكترونية بالوزارة & 8 \\
\hline
\end{tabular}




\begin{tabular}{|c|c|c|c|c|c|c|c|c|}
\hline الموافقة & الترتيب & المزن & $\begin{array}{l}\text { قيمة" } \\
\text { "Sig." }\end{array}$ & $\begin{array}{l}\text { قيمة } \\
\text { "T" }\end{array}$ & المعياري & |المتوسط & الفقرة / المحور & p \\
\hline & & & & & & & نتائج تقييم أداء منصفة & \\
\hline متوسطة & 3 & 65.882 & 0.034 & 2.176 & 1.931 & 6.588 & 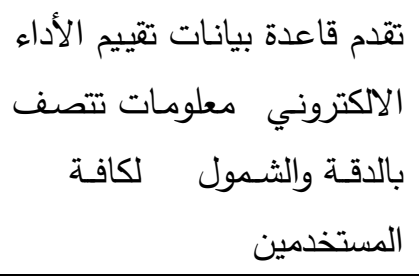 & 9 \\
\hline متوسطة & & 65.88 & 0.018 & 2.456 & 1.710 & 6.588 & نظم معلومات تقييم الأداء & \\
\hline متوسطة & 4 & 61.373 & 0.608 & 0.517 & 1.898 & 6.137 & 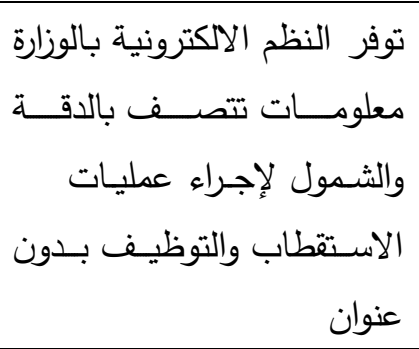 & 10 \\
\hline متوسطة & 5 & 59.020 & 0.736 & -0.340 & 2.062 & 5.902 & 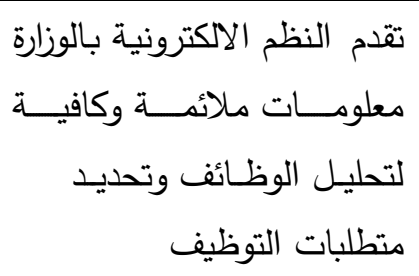 & 11 \\
\hline متوسطة & 1 & 63.725 & 0.174 & 1.380 & 1.928 & 6.373 & 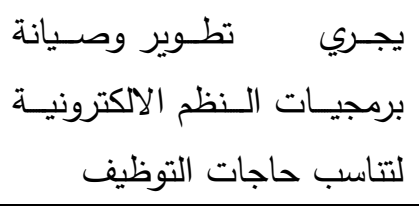 & 12 \\
\hline متوسطة & 2 & 61.765 & 0.533 & 0.628 & 2.007 & 6.176 & 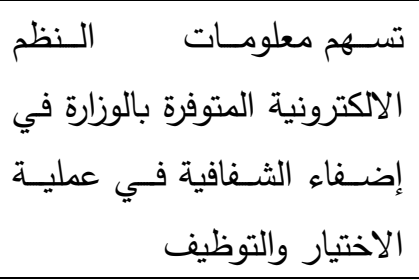 & 13 \\
\hline متوسطة & 3 & 61.412 & 0.578 & 0.560 & 1.799 & 6.141 & 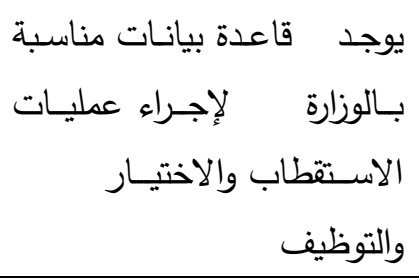 & 14 \\
\hline متوسطة & & 61.17 & 0.690 & 0.401 & 2.094 & 6.118 & نظم معلومات التوظيف & \\
\hline متوسطة & 1 & 56.275 & 0.219 & -1.246 & 2.135 & 5.627 & 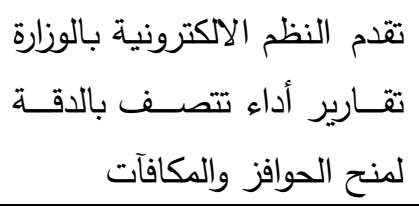 & 15 \\
\hline قليلة & 3 & 51.765 & 0.003 & -3.088 & 1.905 & 5.176 & 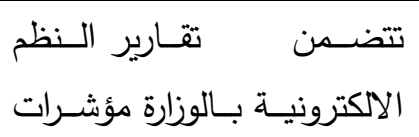 & 16 \\
\hline
\end{tabular}




\begin{tabular}{|c|c|c|c|c|c|c|c|c|}
\hline الموافقة & الترتيب & المزن & $\begin{array}{l}\text { قيمة } \\
\text { "Sig." }\end{array}$ & $\begin{array}{l}\text { قيمة } \\
\text { "T" }\end{array}$ & المعياري & المستوسط & الفقرة / المحور & r \\
\hline & & & & & & & والمكافآت & \\
\hline قليلة & 4 & 51.373 & 0.002 & -3.284 & 1.876 & 5.137 & 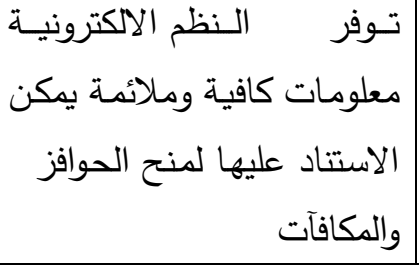 & $1 \longdiv { 3 }$ \\
\hline متوسطة & 2 & 54.314 & 0.072 & -1.836 & 2.211 & 5.431 & 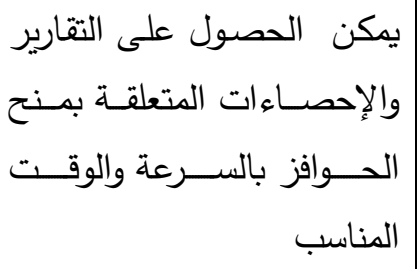 & 18 \\
\hline متوسطة & & 53.43 & 0.015 & -2.524 & 1.859 & 5.343 & نظم معلومات الحوافز & \\
\hline متوسطة & 2 & 59.412 & 0.819 & -0.230 & 1.827 & 5.941 & 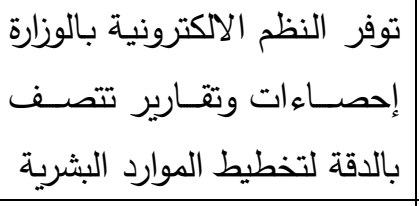 & 19 \\
\hline متوسطة & 1 & 63.333 & 0.272 & 1.112 & 2.142 & 6.333 & 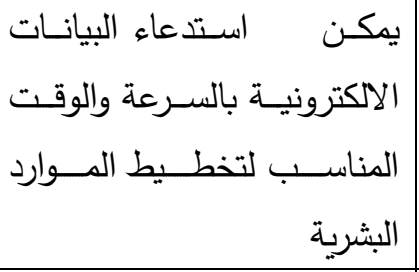 & 20 \\
\hline متوسطة & 4 & 57.843 & 0.376 & -0.893 & 1.724 & 5.784 & 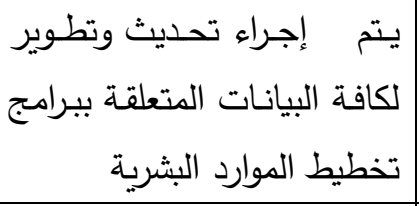 & 21 \\
\hline متوسطة & 3 & 58.039 & 0.440 & -0.778 & 1.800 & 5.804 & لدوجد لداعدة بيانـات مناسبة & 22 \\
\hline متوسطة & & 59.65 & 0.887 & -0.142 & 1.720 & 5.966 & نظم معلومات تخطيط الموارد & \\
\hline متوسطة & & 60.97 & 0.650 & 0.456 & 1.521 & 6.097 & نظم معلومات الموارد البشرية & \\
\hline
\end{tabular}

- واقع تطبيق نظم معلومـات التدريب في وزارة النقل والمواصـلات بقطاع غزة جاء بوزن نسبي (63.686)، وهو بدرجة موافقة متوسطة، ويمكن أن يعزو الباحثون تلك نتيجة في مجال التدريب بعدم كفاية البرامج التدريبية من حيث النوعية والكيفية وأيضاً الضعف الاستفادة من معلومات ومؤشرات التدريب في تحديد الاحتياجات التدريبية بالوزارة.

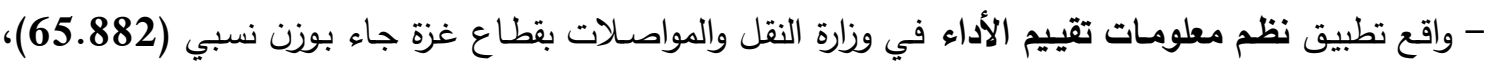
وهو بدرجة موافقة كبيرة، ويمكن أن يرجع الباحثون نتيجة مجال نظم معلومات تقييم الأداء ، بوجود نظام معلوماتي 
للتقييم فاعل، ولكنه يحتاج لتطوير وترقية بحيث يتم الاستفادة القصوى وتعظيمها من المعلومات الخاصـة التقييم في تطوير الأداء الوظيفي في الوزارة. - واقع تطبيق نظم معلومات التوظيف في وزارة النقل والمواصلات بقطاع غزة جاء بوزن نسبي (61.176)؛ وهو بدرجة موافقة كبيرة، ويمكن أن يعزو الباحثون تلك نتيجة في مجال نظم معلومات التوظيف بأنه يوجد معايير جيدة

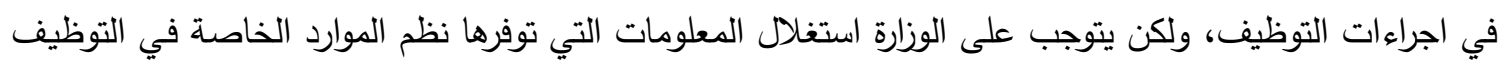
وذلك بتعيين واستقطاب أفضل الكفاءات. - واقع تطبيق نظم معلومـات الحوافز في وزارة النقل والمواصـلات بقطاع غزة جاء بوزن نسبي (53.431)، وهو بدرجة موافقة متوسطة، ويمكن أن يرجع الباحثون نتيجة مجال نظم معلومـات الحوافز، بوجود نظام للحوافز ، ولكنه

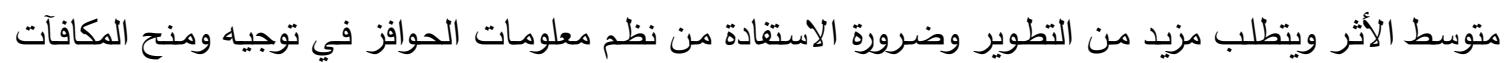
للموظفين. - واقع تطبيق نظم معلومـات تخطيط المـوارد البشرية في وزارة النقل والمواصـلات بقطاع غزة جاء بوزن نسبي

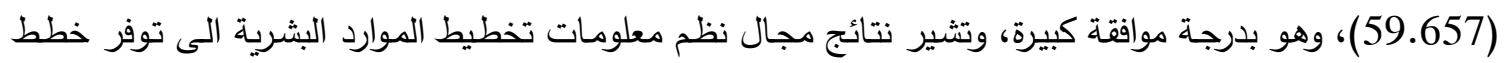
للموارد البشرية، وتستتد على معلومات ومؤشرات بدرجة مرضية ولكنها تتطلب اعادة تطوير لتكون أكثر كفاءة في لئي اعداد خطط الموارد البشرية. - واقع تطبيق نظم معلومات الموارد البشرية في وزارة النقل والمواصلات بقطاع غزة جاء بوزن نسبي (60.971)، وهو بدرجة موافقة كبيرة، ويمكن أن يعزو الباحثون نتيجة كافة مجالات تطبيق نظم معلومات الموارد البشرية بوجود

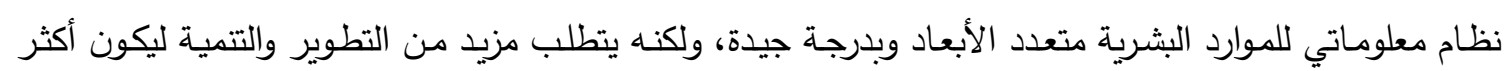
مناسبةً في خطط الموارد، التي يمكن أن تساهم في توليد ونشر المعرفة في الوزارة. نتائج السؤال الثاني:

ينص السؤال على ما يلي: ما مستوى تطبيق إدارة المعرفة في وزارة النقل والمواصلات بقطاع غزة؟ تم الإجابة على هذا السؤال باستخدام اختبار "T" للعينة الواحدة، كما هو مبين في الجدول التالي: لمأي: جدول رقم (4)

تحليل بيانات محاور وفقرات إدارة المعرفة

\begin{tabular}{|c|c|c|c|c|c|c|c|c|}
\hline الموافقة & ا الترتيب & 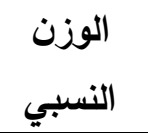 & $\begin{array}{c}\text { قيمة } \\
\text { "Sig." }\end{array}$ & $\begin{array}{l}\text { قيمة } \\
\text { "T" }\end{array}$ & الانحراف & الحتوسط & الفقرة / المحور الثاني & p \\
\hline متوسطة & 3 & 59.412 & 0.819 & -0.230 & 1.827 & 5.941 & 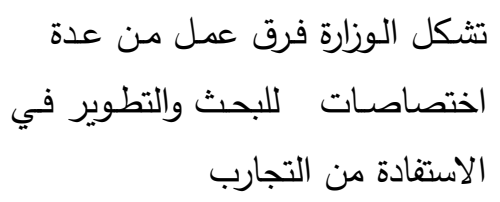 & 1 \\
\hline متوسطة & 1 & 63.333 & 0.272 & 1.112 & 2.142 & 6.333 & 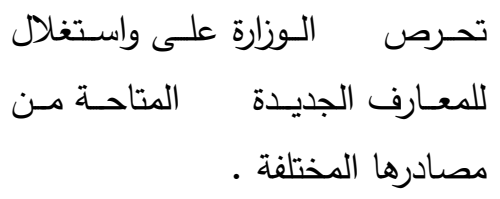 & 2 \\
\hline متوسطة & 5 & 57.843 & 0.376 & -0.893 & 1.724 & 5.784 & 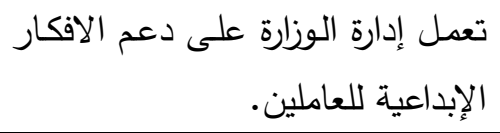 & 3 \\
\hline متوسطة & 4 & 58.039 & 0.440 & -0.778 & 1.800 & 5.804 & تحرص الـوزارة علـى إقامـة الندوات & 4 \\
\hline
\end{tabular}




\begin{tabular}{|c|c|c|c|c|c|c|c|c|}
\hline الموافقة & الترتيب & 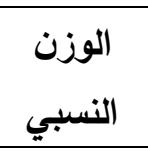 & $\begin{array}{c}\text { قيمة } \\
\text { "Sig." }\end{array}$ & $\begin{array}{l}\text { قيمة } \\
\text { "T" }\end{array}$ & الانحراف & المتوسط & الفقرة / المحور الثاني & p \\
\hline & & & & & & & 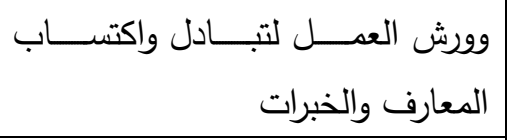 & \\
\hline | متوسطة & 2 & 59.657 & 0.887 & -0.142 & 1.720 & 5.966 & 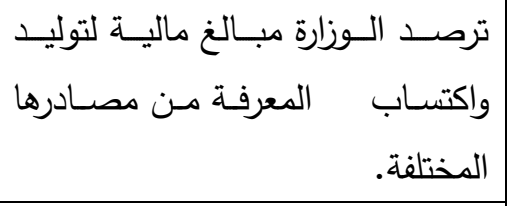 & 54 \\
\hline متوسطة & & 60.97 & 0.650 & 0.456 & 1.521 & 6.097 & توليد تخزين & \\
\hline | متوسطة & 1 & 57.255 & 0.327 & -0.990 & 1.981 & 5.725 & من خلال تكنولوجيا معلومات حديثة. & 6 \\
\hline | متوسطة & 2 & 54.510 & 0.043 & -2.074 & 1.890 & 5.451 & 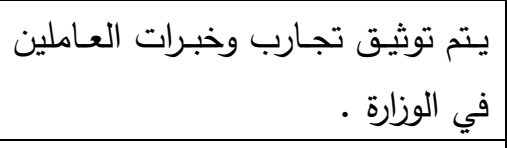 & 7 \\
\hline | متوسطة & 3 & 54.314 & 0.068 & -1.867 & 2.175 & 5.431 & 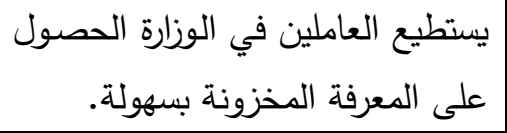 & 8 \\
\hline | متوسطة & 4 & 52.745 & 0.026 & -2.298 & 2.255 & 5.275 & 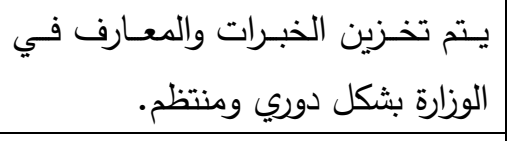 & 9 \\
\hline متوسطة & & 48.23 & 0.000 & -4.250 & 1.977 & 4.824 & تخزين المعرفة & \\
\hline | متوسطة & 4 & 53.412 & 0.017 & -2.467 & 1.907 & 5.341 & 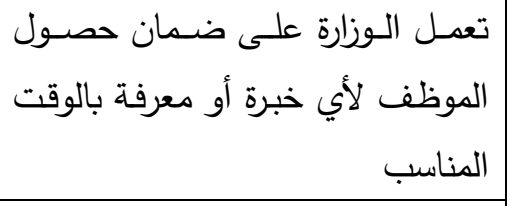 & 10 \\
\hline | متوسطة & 1 & 55.294 & 0.129 & -1.545 & 2.176 & 5.529 & 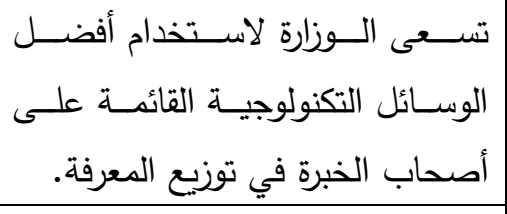 & 11 \\
\hline قليلة & 5 & 49.608 & 0.001 & -3.588 & 2.068 & 4.961 & 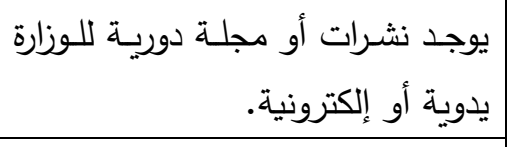 & 12 \\
\hline | متوسطة & 3 & 53.922 & 0.041 & -2.097 & 2.070 & 5.392 & 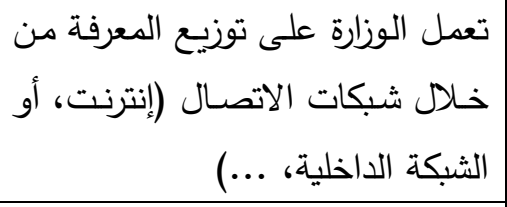 & 13 \\
\hline | متوسطة & 2 & 54.118 & 0.055 & -1.966 & 2.137 & 5.412 & 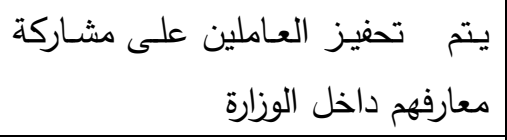 & 14 \\
\hline متوسطة & & 53.23 & 0.016 & -2.489 & 1.941 & 5.324 & نشر وتوزيع المعرفة & \\
\hline قليلة & 5 & 51.765 & 0.014 & -2.543 & 2.313 & 5.176 & 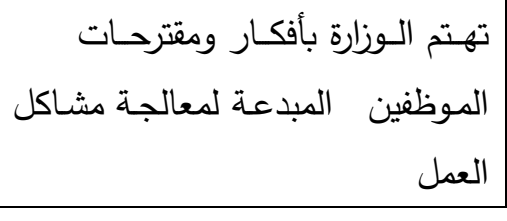 & 15 \\
\hline
\end{tabular}




\begin{tabular}{|c|c|c|c|c|c|c|c|c|}
\hline الموافقة & الترتيب & 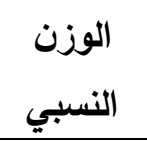 & $\begin{array}{c}\text { قيمة } \\
\text { "Sig." }\end{array}$ & قيمة & المعياري - الافي & المسابي & الفقرة / المحور الثاني & م \\
\hline متوسطة & 3 & 53.529 & 0.056 & -1.954 & 2.365 & 5.353 & لتطبيـق الافكـار والابداعيـة لتطـوير كافـة الوسـائل & 16 \\
\hline متوسطل & 2 & 54.118 & 0.057 & -1.949 & 2.156 & 5.412 & بتطبيق معارفهر. & 17 \\
\hline متوسطة & 1 & 55.098 & 0.068 & -1.862 & 1.880 & 5.510 & | تطبق الـوزارة مـا لـديها مـن خبـرات & 18 \\
\hline قليلة & 4 & 51.373 & 0.007 & -2.812 & 2.191 & 5.137 & 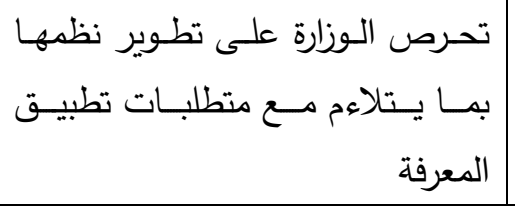 & 19 \\
\hline متوسطة & & 53.17 & 0.015 & -2.510 & 1.942 & 5.318 & تطبيق المعرفة & \\
\hline متوسطة & & 50.58 & 0.003 & -3.142 & 2.139 & 5.059 & إدارة المعرفة & \\
\hline
\end{tabular}

وقد تبين من الجدول السابق أن: - مستوى تطبيق توليد المعرفة في وزارة النقل والمواصلات بقطاع غناع غزة جاء بوزن نسبي (60.971)، وهو بدرجة موافقة كبيرة، ويمكن أن يعزو الباحثون نتيجة مجال توليد المعرفة بوجود اهتمام مناسب في تثجيع أفكار واقتراحات العاملين في الوزارة، ولكنه يوجد فاقد في استغلال أكثر كفاءةً لقدرات العاملين الكامنة وتوجيهـها بأفكار ابداعية تعزز وتتمي الأداء الوظيفي. - مستوى تطبيق تخزين المعرفة في وزارة النقل والمواصلات بقطاع غزة جاء بوزن نسبي (48.235)، وهو بدرجة

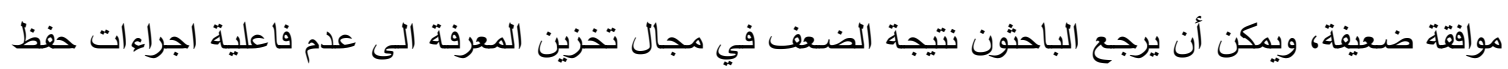

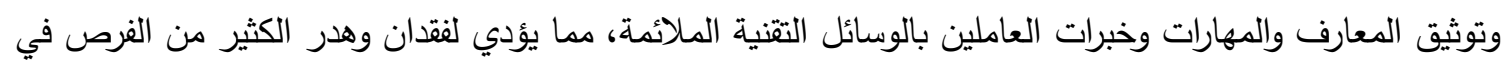
استغلال قدرات ومعارف الموهوبين من العاملين في الوزارة، واستغلالها في حل المشاكل وتطوير الأداء.

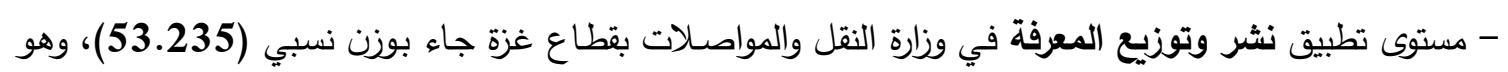

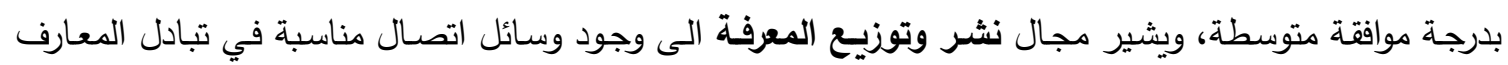

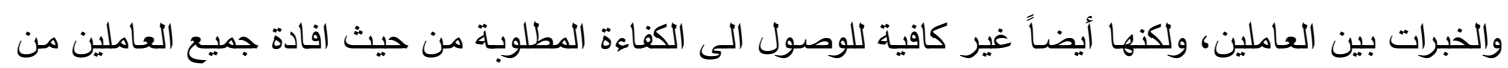
المعارف المتاحة بطرق عالية التقنية. - مستوى تطبيق المعرفة في وزارة النقل والمواصلات بقطاع غزة جاء بوزن نسبي (53.176)، وهو بدرجة موافقة

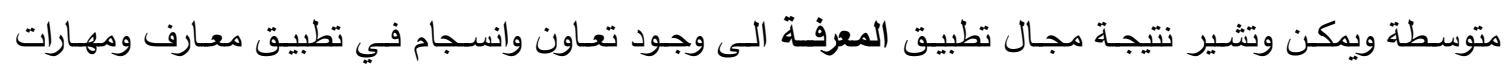

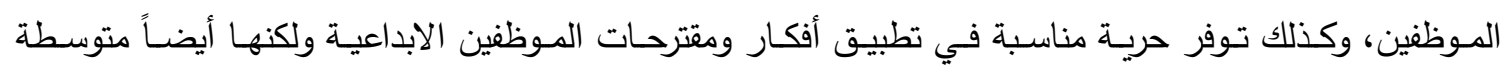
المستوى، وتتطلب مزيد من التطوير في الوزارة.

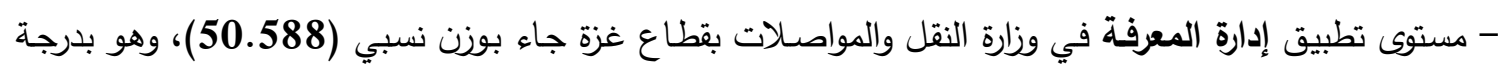
موافقة متوسطة، ويمكن أن يرجع الباحثون النتيجة المتوسطة في مجال إدارة المعرفة أنه توجد ممارسات في توليد 
وتطبيق ونشر وتخزين المعرفة وبأشكال متعددة، ولكنها متوسطة الأثر ، وتتطلب مزيد من المجهودات في نواحي

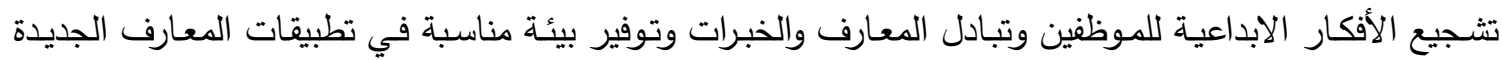
بالوزارة.

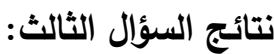
ينص السؤال على ما يلي: هل يوجد علاقة بين واقع تطبيق نظم معلومات الموارد البشرية وبين مستوى تطبيق

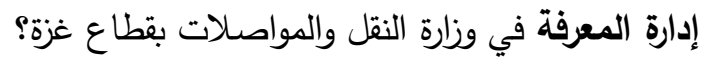
ولإجابة على هذا السؤال تم صياغة الفرضية التالية: لا يوجد علاقة ذات دلالة إحصائية عند مستوى دلالة (20.05) بين واقع تطبيق نظم معلومـات الموارد البثرية

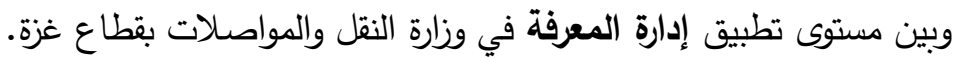
تم التحقق من صحة هذه الفرضية عن طريق إيجاد معاملات ارتباط بيرسون، كما هو مبين في الجدول التالي:

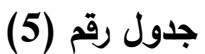

معاملات ارتباط بيرسون بين نظم معلومات الموارد البشرية وبين إدارة المعرفة

\begin{tabular}{|c|c|c|c|c|c|c|}
\hline معلومات & معلومات & معلومات & معلومات & تقعيم الأداء & نظم معلومات & المحور \\
\hline 0.866 & 0.748 & 0.852 & 0.809 & 0.592 & 0.684 & توليد المعرفة \\
\hline 0.867 & 0.787 & 0.869 & 0.848 & 0.561 & 0.626 & تخزين المعرفة \\
\hline 0.860 & 0.739 & 0.839 & 0.815 & 0.600 & 0.665 & نشر وتوزيـع المعرفة \\
\hline 0.778 & 0.722 & 0.820 & 0.743 & 0.558 & 0.493 & تطبيق المعرفة \\
\hline 0.878 & 0.779 & 0.880 & 0.836 & 0.603 & 0.644 & إدارة المعرفة \\
\hline
\end{tabular}

* قيمة "ر : معامل ارتباط بيرسون" عند درجة حرية (50) ومستوى دلالة (0.05) = (0.273). وقد تبين من الجدول السابق أن: معاملات ارتباط بيرسون بين نظم معلومات الموارد البثرية وبين إدارة المعرفة دالة إحصائياً، وهذا يدل على وجود

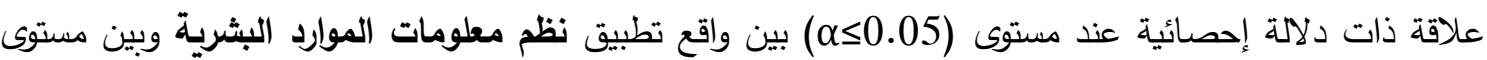
تطبيق إدارة المعرفة في وزارة النقل والمواصلات بقطاع غزة، وتوضح هذه النتيجة دور معلومات نظم التدريب والتوظيف والحوافز وتخطيط الموارد في تعزيز تطبيق ادارة المعرفة في الوزارة ، وأنه كلما زادت كفاءة مخرجات نظم معلومات الموارد البشرية واستغلالها كمؤشرات تطويرية فإنها تحسن وتسهل تطبيق ادارة المعرفة، وأن الوزارة تعتني في نظم معلومات الموارد البشرية لديها حرصاً منها على تطبيق كفه لإدارة المعرفة.

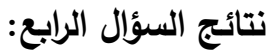

ينص السؤال على ما يلي: هل يوجد أثر بين واقع تطبيق نظم معلومات الموارد البشرية وبين مستوى تطبيق إدارة المعرفة في وزارة النقل والمواصلات بقط ملاع غزة؟ 
وللإجابة على هذا السؤال تم صياغة الفرضية التالية: لا يوجد أثر ذو دلالة إحصائية عند مستوى دلالة (1>0.05) بين واقع تطبيق نظم معلومـات الموارد البشرية وبين

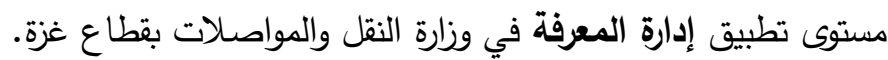
تم التحقق من صحة هذه الفرضية باستخدام تحليل الانحدار الخطي (Linear Regression Analysis)، كما هو مبين في الجدول التالي:

جدول رقم (6)

\begin{tabular}{|c|c|c|c|c|}
\hline الدلالة الد & $\begin{array}{c}\text { قيمة } \\
\text { "Sig." }\end{array}$ & $\begin{array}{l}\text { قيمة } \\
\text { "T" }\end{array}$ & الانحدار معامل & المتغيرات المستقلة المتلة \\
\hline غير دالة & 0.607 & 0.518 & 0.237 & المتغير الثابت \\
\hline 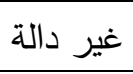 & 0.850 & 0.190 & 0.017 & نظم معلومات التدريب \\
\hline 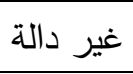 & 0.739 & 0.335 & 0.029 & نظم معلومات تقييم الأداء \\
\hline 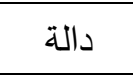 & 0.000 & 3.808 & 0.410 & نظم معلومات التوظيف \\
\hline 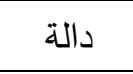 & 0.000 & 6.389 & 0.579 & نظم معلومات الحوافز \\
\hline 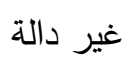 & 0.607 & 0.518 & 0.237 & نظم معلومات تخطيط الموارد البشرية \\
\hline \multicolumn{5}{|c|}{ 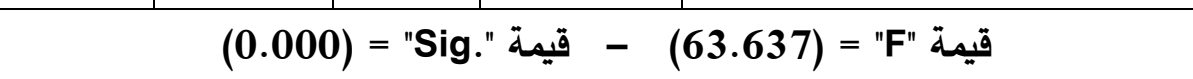 } \\
\hline \multicolumn{5}{|c|}{ معامل التحديد = (0.847) - - معامل التحديد المعدل = (0.834) } \\
\hline
\end{tabular}

$$
\begin{aligned}
& \text { * قيمة "T" الجدولية عند درجة حرية (50) وعند مستوى دلالة (0.05) = (2.000). } \\
& \text { وقد تبين من الجدول السابق أن: }
\end{aligned}
$$

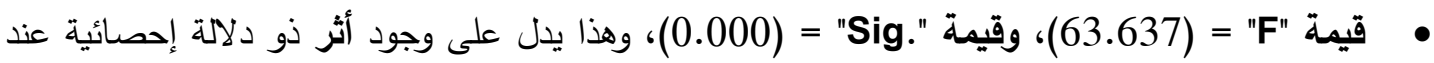
مستوى دلالة (م<0.05) بين واقع تطبيق نظم معلومات الموارد البثرية وبين مستوى تطبيق إدارة المعرفة في وزارة النقل والمواصلات بقطاع غزة.

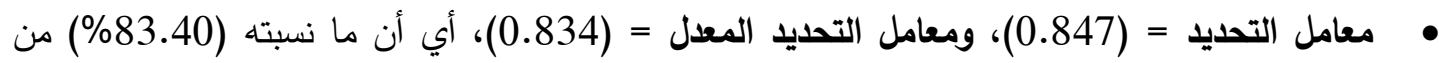

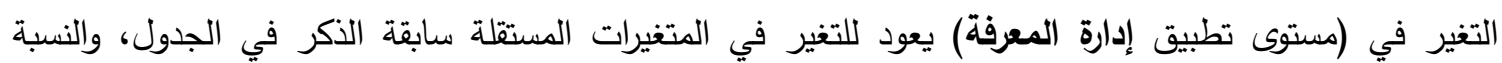
المتبقية تعود للتغير في عوامل أخرى. • المتغيرات ذات دلالة إحصائية هي: (نظم معلومات التوظيف، نظم معلومات الحوافز)، أي أنها تؤثر في (مستوى تطبيق إدارة المعرفة). • المتغيرات ليست ذات دلالة إحصائية هي: (المتغير الثابت، نظم معلومات التدريب، نظم معلومات تقييم الأداء، نظم معلومات تخطيط الموارد البشرية)، أي أنها لا تؤثر في (مستوى تطبيق إلهئ إدارة المعرفة).

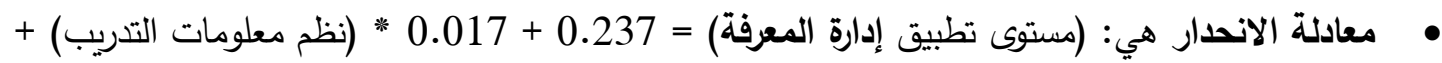
0.029 * (نظم معلومات تقييم الأداء) + 0.410 * (نظم معلومات التوظيف) + 0.579 * (نظم معلومات الحوافز) + 0.237 * (نظم معلومات تخطيط الموارد البشرية). 
نتائَج السؤال الخامس: ينص السؤال على ما يلي: هل يوجد فروق في استجابات أفراد عينة الدراسة حول واقع تطبيق نظم معلومات الموارد البشرية وحول مستوى تطبيق إدارة المعرفة في وزارة النقل والمواصلات بقطاع غزة تعزى لمتغيرات: (المسمى فرى

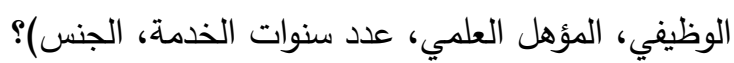
ولإجابة على هذا السؤال تم صياغة الفرضية التالية:

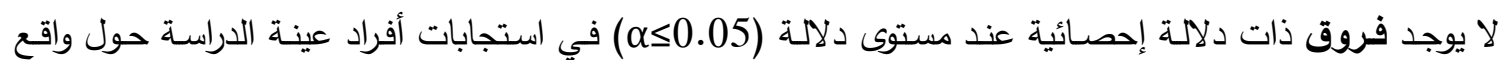

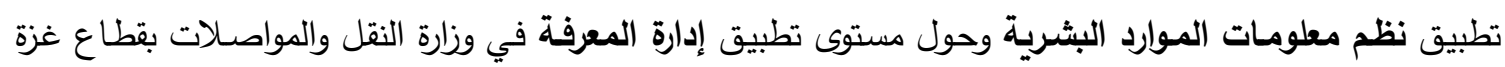
تعزى لمتغيرات: (المسمى الوظيفي، المؤهل العلمي، عدد سنوات الخدمة، الجنس). ويتفرع من الفرضية الرئيسة السابقة الفرضيات الفرعية التالية:

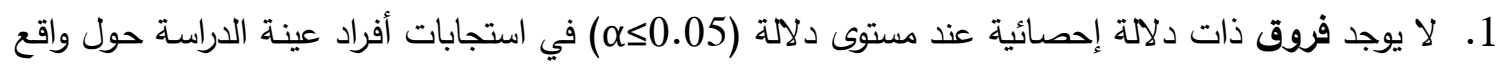

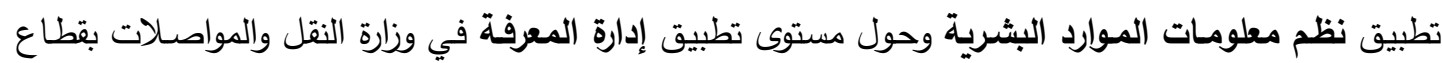
غزة تعزى لمتغير المسمى الوظيفي. تم التحقق من صحة هذه الفرضية عن طريق اختبار One-Way ANOVA، كما هو مبين في الجدول التالي: جدول رقم (7)

\begin{tabular}{|c|c|c|c|c|c|c|c|}
\hline \multicolumn{8}{|c|}{ الفروقات بالنسبة لمتغير المسمى الوظيفي } \\
\hline 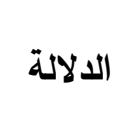 & $\begin{array}{c}\text { قيمة } \\
\text { "Sig." }\end{array}$ & $\begin{array}{l}\text { قيمة } \\
\text { "F" }\end{array}$ & الانحراف & الحستوسط الحسي & 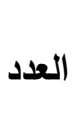 & المسمى الوظيفي & 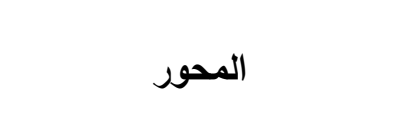 \\
\hline \multirow{4}{*}{ غير دالة } & \multirow{4}{*}{0.963} & \multirow{4}{*}{0.093} & 1.522 & 6.295 & 6 & رئيس شعبة & \multirow{4}{*}{ نظم معلومات الموارد البشرية } \\
\hline & & & 1.848 & 5.920 & 13 & رئيس قسم & \\
\hline & & & 1.527 & 6.131 & 24 & مدير دائرة & \\
\hline & & & 1.122 & 6.136 & 8 & مدير عام & \\
\hline \multirow{4}{*}{ 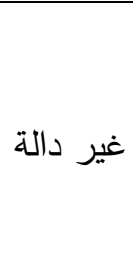 } & \multirow{4}{*}{0.808} & \multirow{4}{*}{0.324} & 1.809 & 5.649 & 6 & رئيس شعبة & \multirow{4}{*}{ إدارة المعرفة } \\
\hline & & & 2.241 & 4.927 & 13 & رئيس قسم & \\
\hline & & & 1.741 & 5.303 & 24 & مدير دائرة & \\
\hline & & & 1.639 & 5.632 & 8 & مدير عام & \\
\hline
\end{tabular}

$$
\text { * قيمة "F" الجدولية عند درجة حرية (3، 47) وعند مستوى دلالة (0.05) = (2.810). }
$$
وقد تبين من الجدول السابق أن:

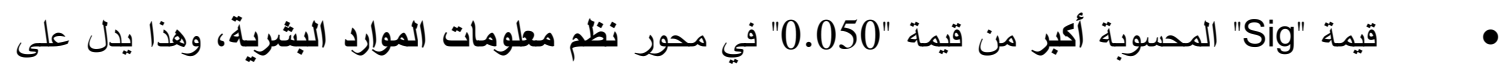

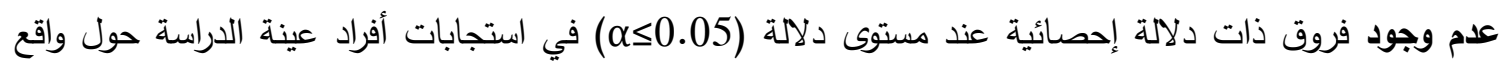
تطبيق نظم معلومات الموارد البشرية في وزارة النقل والمواصلات بقطاع غزة تعزى لمتغير المسمى الوظيفي.

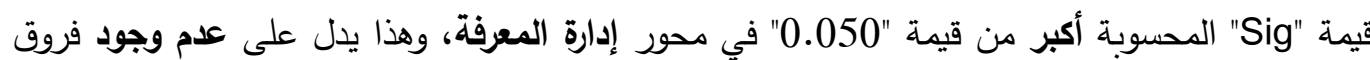
ذات دلالة إحصائية عند مستوى دلالة (1<0.05) في استجابات أفراد عينة الدراسة حول مستوى تطبيق إدارة المعرفة في وزارة النقل والمواصلات بقطاع غزة تعزى لمتغير المسمى الوظيفي. 
1. لا يوجد فروق ذات دلالة إحصائية عند مستوى دلالة (0.05 م) في استجابات أفراد عينـة الدراسة حول واقع

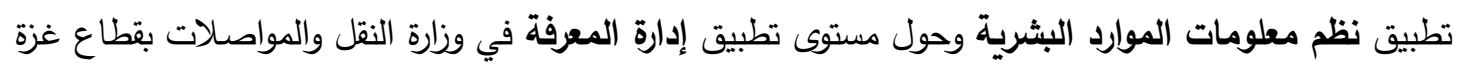
تعزى لمتغير المؤهل العلمي. تم التحقق من صحة هذه الفرضية عن طريق اختبار One-Way ANOVA، كما هو مبين في الجدول التالي: جدول رقم (8)

\begin{tabular}{|c|c|c|c|c|c|c|c|}
\hline الدلالة & $\begin{array}{c}\text { قيمة } \\
\text { "Sig." }\end{array}$ & $\begin{array}{l}\text { قيمة } \\
\text { "F" }\end{array}$ & الانحراف & الحستوسطي & العدد & المؤهل العلمي & المحور \\
\hline \multirow{3}{*}{ غير دالة } & \multirow{3}{*}{0.178} & \multirow{3}{*}{1.787} & 1.270 & 5.979 & 11 & دبلوم متوسط & \\
\hline & & & 1.424 & 6.385 & 30 & بكالوريوس & \\
\hline & & & 1.906 & 5.364 & 10 & دراسات عليا & \\
\hline \multirow{3}{*}{ غير دالة } & \multirow{3}{*}{0.356} & \multirow{3}{*}{1.056} & 1.667 & 4.809 & 11 & دبلوم متوسط & \multirow{3}{*}{ إدارة المعرفة } \\
\hline & & & 1.798 & 5.611 & 30 & بكالوريوس & \\
\hline & & & 2.106 & 4.905 & 10 & دراسات عليا & \\
\hline
\end{tabular}

* قيمة "F" الجدولية عند درجة حرية (2، 48) وعند مستوى دلالة (0.05) = (3.180). وقد تبين من الجدول السابق أن:

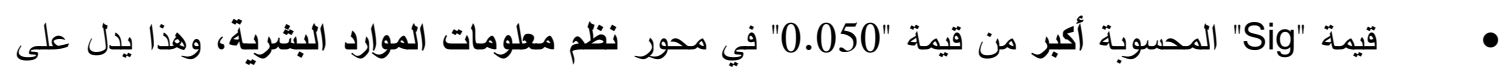

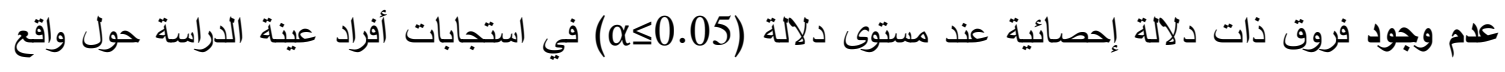

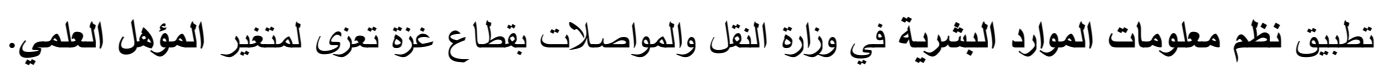

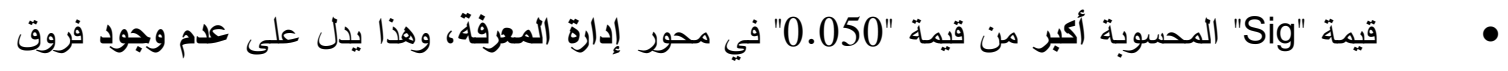
ذات دلالة إحصائية عند مستوى دلالة (1<0.05) في استجابات أفراد عينة الدراسة حول مستوى تطبيق إدارة المعرفة في وزارة النقل والمواصلات بقطاع غزة تعزى لمتغير المؤهل العلمي.

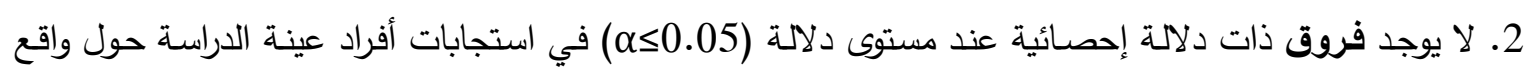

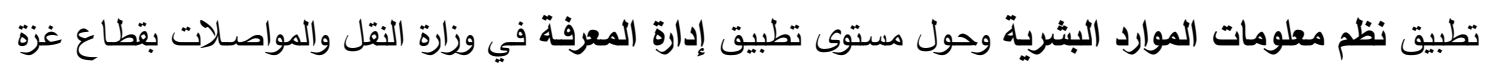
تعزى لمتغير عدد سنوات الخدمة. تم التحقق من صحة هذه الفرضية عن طريق اختبار One-Way ANOVA، كما هو مبين في الجدول التالي: جدول رقم (9)

الفروقات بالنسبة لمتغير عدد سنوات الخدمة

\begin{tabular}{|c|c|c|c|c|c|c|c|}
\hline الالالة الالة & $\begin{array}{c}\text { قيمة } \\
\text { "Sig." }\end{array}$ & $\begin{array}{l}\text { قيمة } \\
\text { "F" }\end{array}$ & الالمعراف & الحسابي & 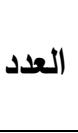 & عدد سنوات الخدمة & المحور \\
\hline \multirow{3}{*}{ غير دالة } & \multirow{3}{*}{0.542} & \multirow{3}{*}{0.621} & 1.562 & 6.500 & 5 & من 5-أقل من 10 سنوات & \multirow{3}{*}{ نظم معلومات الموارد البشرية } \\
\hline & & & 1.609 & 5.915 & 32 & من 10-أقل من 15 سنة & \\
\hline & & & 1.323 & 6.370 & 14 & 15 سنة فأكثر & \\
\hline غير دالة & 0.102 & 2.396 & 1.268 & 6.116 & 5 & من 5-أقل من 10 سنوات & إدارة المعرفة \\
\hline
\end{tabular}




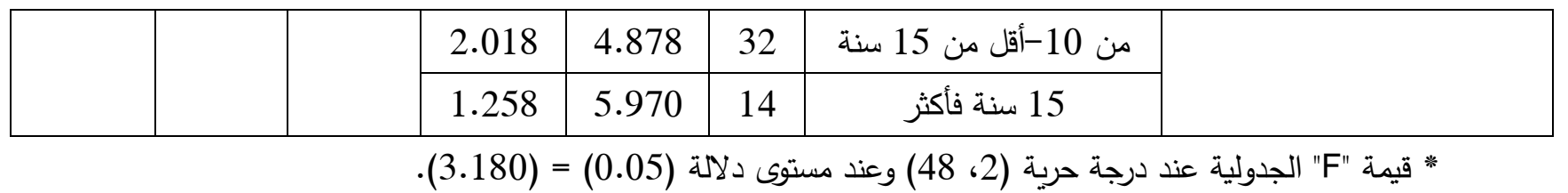

وقد تبين من الجدول السابق أن:

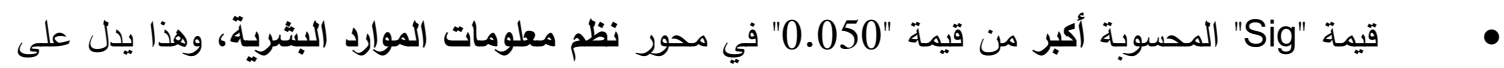

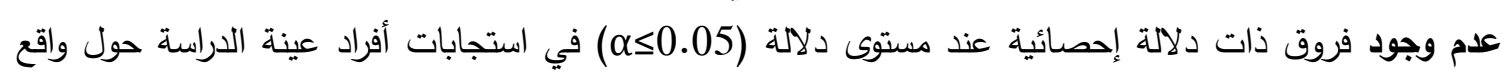

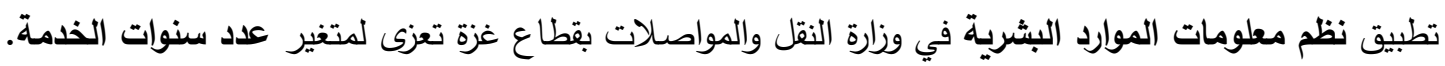

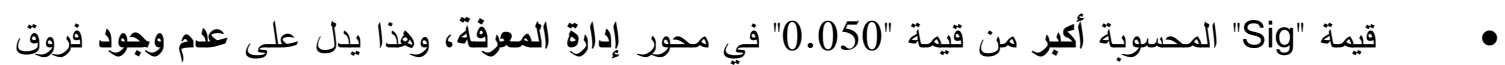
ذات دلالة إحصائية عند مستوى دلالة (1<0.05) في استجابات أفراد عينة الدراسة حول مستوى تطبيق إدارة المعرفة في وزارة النقل والمواصلات بقطاع غزة تعزى لمتغير عدد سنوات الخدات الخدمة.

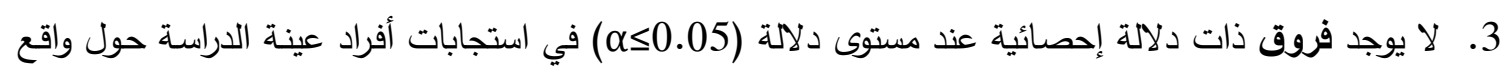

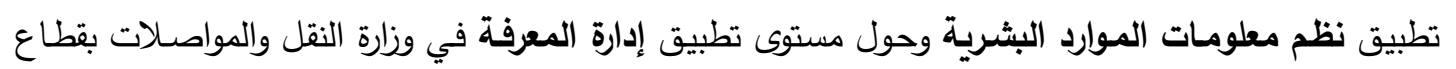
غزة تعزى لمتغير الجنس. تم التحقق من صحة هذه الفرضية عن طريق اختبار T-Test، كما هو مبين في الجدول التالي: جدول رقم (10) - (10)

الفروقات بالنسبة لمتغير الجنس

\begin{tabular}{|c|c|c|c|c|c|c|c|}
\hline الدلالة & $\begin{array}{c}\text { قيمة" } \\
\text { "Sig." }\end{array}$ & $\begin{array}{l}\text { قيمة } \\
\text { "T" }\end{array}$ & الانحراف & الحسابي & العدد & الجنس & المحور \\
\hline \multirow{2}{*}{ غير دالة } & \multirow{2}{*}{0.495} & \multirow{2}{*}{-0.687} & 1.612 & 6.043 & 45 & ذكر & \multirow{2}{*}{ نظم معلومات الموارد البشرية } \\
\hline & & & 0.244 & 6.500 & 6 & أنثى & \\
\hline \multirow{2}{*}{ غير دالة } & \multirow{2}{*}{0.492} & \multirow{2}{*}{-0.693} & 1.873 & 5.234 & 45 & ل ذكر & \multirow{2}{*}{ إدارة المعرفة } \\
\hline & & & 1.584 & 5.789 & 6 & أنثى & \\
\hline
\end{tabular}

$$
\text { " قيمة "T" الجدولية عند درجة حرية (49) وعند مستوى دلالة (0.05) = (2.000). }
$$
وقد تبين من الجدول السابق أن:

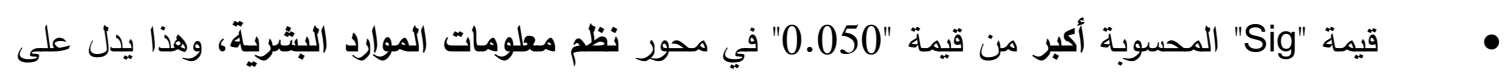

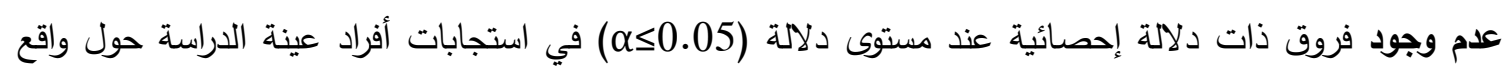

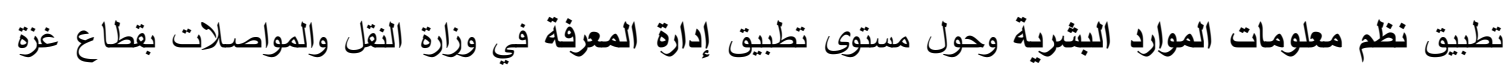
تعزى لمتغير الجنس. • قيمة "Sig" المحسوبة أكبر من قيمة "0.050" في محور إدارة المعرفة، وهذا يدل على عدم وجود فروق ذات دلالة إحصائية عند مستوى دلالة (1<0.05) في استجابات أفراد عينة الدراسة حول واقع تطبيق نظم

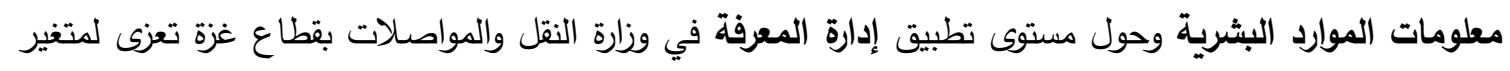
الجنس. 
النتائج والتوصيات:

توصلت الدراسة إلى النتائج والتوصيات التالية:

أولا: النتائج:

أ.النتائج الخاصة بنظم معلومات الموارد البشرية

- اتضح وجود علاقة ذات دلالة إحصائية عند مستوى (00.05) ايجابية بين واقع تطبيق نظم معلومات

الموارد البشرية وبين مستوى تطبيق إدارة المعرفة في وزارة النقل بقطاع غزة. - - تبين وجود أثر ذو دلالة إحصائية عند مستوى دلالة (0.05) بين واقع تطبيق نظم معلومات الموارد

البشرية وبين مستوى تطبيق إدارة المعرفة بنسبة (83.40\%) في الوزارة. - اتضح أن توافر تطبيقات نظم معلومات الموارد البشرية في وزارة النقل والمواصـلات بقطاع غزة جاء بوزن إنت نسبي (60.971)، وهو بدرجة موافقة متوسطة في كافة دوائر وأقسام الوزارة

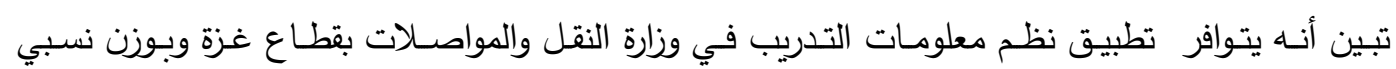
(63.686)، وهو بدرجة موافقة متوسطة اتضح أن هناك توافر في تطبيق نظم معلومات تقييم الأداء في وزارة النقل بغزة وبوزن نسبي (65.882)، وهو بدرجة موافقة متوسطة - - ظهر أنه يتوافر تطبيق نظم معلومات التوظيف في وزارة النقل بغزة وبوزن نسبي (61.176)، وهو بدرجة موافقة متوسطة.

اتضـح أنه يتوافر تطبيق نظم معلومات الحوافز في وزارة النقل بغزة وبوزن نسبي (53.431)، وهو بدرجة موافقة متوسطة.

- تبين أنه يتوافر تطبيق نظم معلومات تخطيط الموارد البشرية في وزارة النقل بغزة وبوزن نسبي (59.657)؛ وهو بدرجة موافقة (متوسط). ب. النتائج الخاصة بإدارة المعرفة - اتضح أن مستوى تطبيقات إدارة المعرفة جاء بدرجة موافقة ضعيفة بالوزارة وبوزن نسبي (50.588). - تبين أن مستوى تطبيق توليد المعرفة جاء بدرجة موافقة متوسطة بالوزارة وبوزن نسبي (60.971). - اتضح أن تطبيق تخزين المعرفة جاء بدرجة موافقة ضعيفة في الوزارة وبوزن نسبي (48.235). - تبين أن مستوى تطبيق نشر وتوزيع المعرفة جاء بدرجة موافقة متوسطة بالوزارة وبوزن نسبي (53.235). - ظهر أن مستوى تطبيق المعرفة جاء بدرجة موافقة متوسطة في الوزارة وبوزن نسبي (53.176). ثانيًا: التوصيات:

أ. التوصيات الخاصة بنظم معلومات الموارد البشرية

- ضرورة الاهتمام في مكونات نظم معلومات الموارد البشرية كمحور استراتيجي في توليد ونشر المعرفة بالوزارة.

- العمل على تطوير واعادة تصميم برامج التدريب وفقاً لمخرجات نظم معلومات التدريب وبما يخدم تعزيز ادارة المعرفة في الوزارة - الاستمرار في ترقية وتحسين نظم معلومات تقييم الأداء، والاستفادة من مؤشراتها في معالجة نقاط الضعف وتعزيز ممكنات العاملين لدى الوزارة. 
- ضرورة اجراء التعيين والاستقطاب بناء على مؤشرات نظم معلومات التوظيف في الوزارة لتحسين النوعية في الاختيار والتعيين.

- ضرورة اعادة تصميم نظام متكامل للحوافز والمكافآت أكثر كفاءة استتاداً على مؤشرات نظم معلومات الحوافز، بما يضمن تحقيق العدالة التظيمية ويساهم بنشر المعرفة بين موظفي الوزارة.

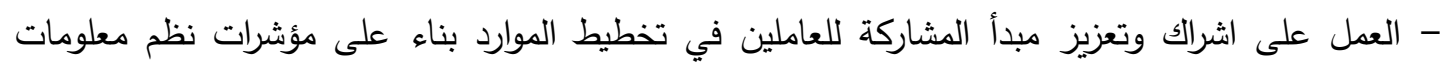
تخطيط الموارد، وبما يضمن فاعلية بالإنتاجية الفردية ويسهل نشر المعرفة والتعلم بالوزارة. ت. التوصيات الخاصة بإدارة المعرفة - - ضرورة تعزيز دعم توليد ونشر المعرفة بما يحفز الابداع وتبادل الخبرات بين العاملين، كذلك الاستفادة من المهارات والمعارف المتراكمة لدى العاملين بالوزارة.

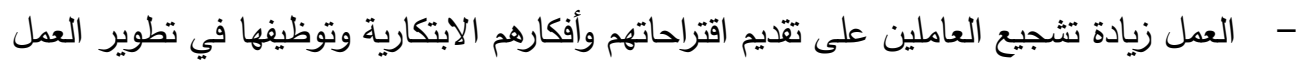

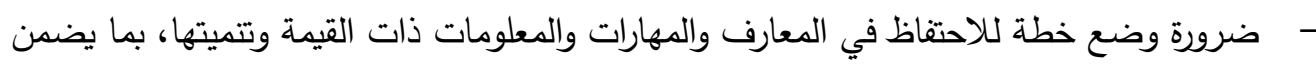
استرجاعها في الوقت والكيفية الفاعلة. - -

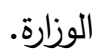

الحداد، عوني بدير • (2003). مبادئ السلوك التنظيمي في المؤسسات، الاسماعيلية: جامعة قناة السويس.

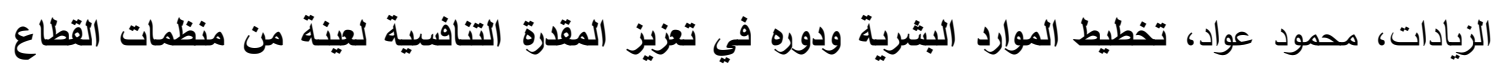

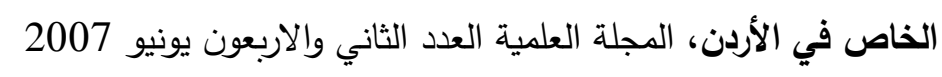

الثنطي، محمود عبدالرحمن إبراهيم، (2017)،"دور القيادة التحويلية في عمليات إدارة المعرفة: دراسة تطبيقية

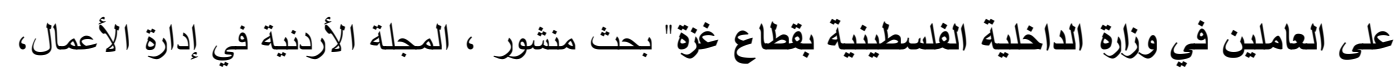

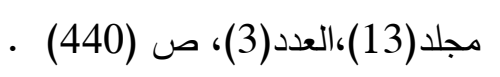
الطيطي، خضر مصباح. (2011). إدارة التغيير التحديات والاستراتيجيات للمدراء المعاصرين، ط1، عمان: دار صلار الحامد للنشر والتوزيع.

العاني، مزهر • (2012). ذكاء الأعمال وتكنولوجيا المعلومات، ط1، عمان: دار صفاء للنشر والتوزيع.

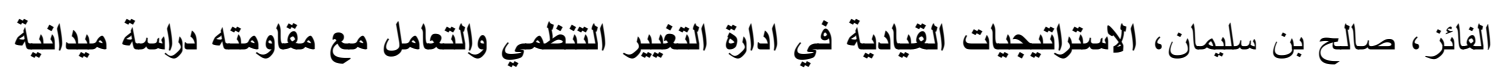

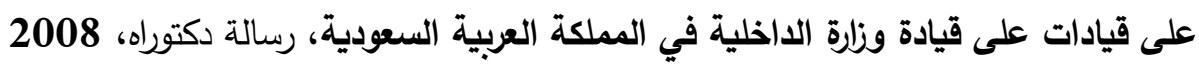

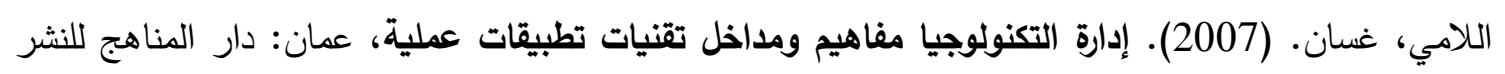
والتوزيع.

بن سماحة، عفاف، أثر إدارة التغيير التظيمي على الابتكار في المؤسسات الصغيرة و المتوسطة دراسة حالة بعض المؤسسات الصناعية- غرداية، رسالة ماجستير، جامعة قاصدي مرباح، الجزائر . 2013.

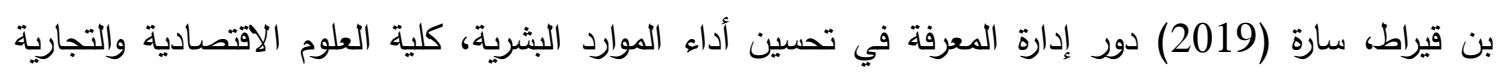
وعلوم التسيير قسم العلوم الاقتصادية، الجزائر رسالة ماجستير تقرير الاحصاء الفلسطيني للتعداد السكاني 2017 تقرير وزارة النقل والمواصلات ادارة التخطيط غزة للعام 2016 صادر 2017 
تقرير وزارة النقل والمواصلات ادارة التخطيط غزة للعام 2017 صادر 2018

تقرير وزارة النقل والمواصلات ادارة التخطيط غزة للعام 2018 صادر 2019

جاد الرب، سيد محمد. (2008). مراجع إدارة الأعمال الاتجاهات الحديثة في إدارة المنظمات الصحية، القاهرة: مطبعة العشري.

جاد الرب، سيد محمد، نظم المعلومات الإدارية الأساسيات وإلتطبيقات الإدارية، الإسماعيلية، دار الصفاء للطباعة

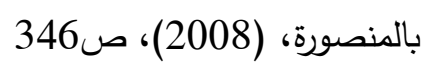

جاد الرب، محمد سيد، (2009)، "الاتجاهات الحديثة في إدارة الأعمال"، دار الكتب المصرية، ص ص صلاكس 525.526

جاد الرب، محمد سيد، (2015)، "الاتجاهات الحديثة في إدارة المخاطر والأزمات"، دار الكتب المصرية، ص .177

حسن أيوب أيوب، التطورات التكنولوجية وآثارها على الموارد البشرية بالمنظمات الصناعية المصرية، مجلة البحوث

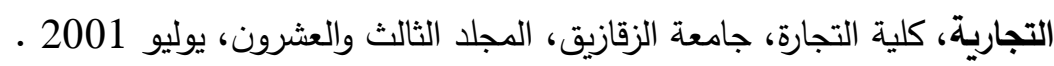

زمام، نور ، سليماني، صباح، (2013). تطور مفهوم التكنولوجيا واستخداماته في العملية التعليمية، مجلة العلوم

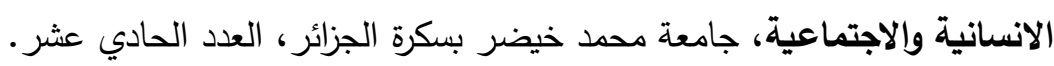

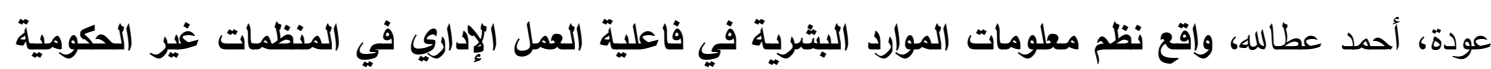
في قطاع غزة، رسالة ماجستير 2013

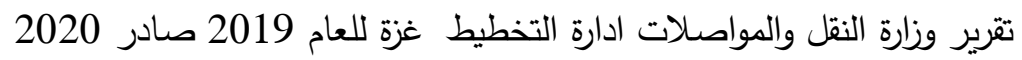
عتيقة، بن طاطة، أثر نظام معلومات الموارد البثرية على فاعلية التسيير التقديري للوظائف والكفاءات دراسة ميدانية في البنوك الجزائرية، كلية العلوم الاقتصادية والتجارية وعلوم التسيير الملتقى الوطني الثاني حول

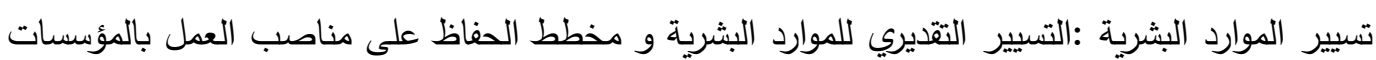

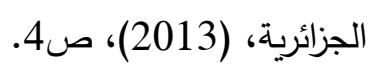

\section{References}

Alageeli, O. M., \& Aalyateem, A. M. A. (2015). The role of the tacit knowledge in developing the human resources: Critical analytical study of the knowledge centre in the industrial commercial chamber in Jeddah, the Kingdom of Saudi Arabia. Procedia Computer Science, 65, 469-478. https://doi.org/10.1016/j.procs.2015.09.123

Al-Ani, M. (2012). Business intelligence and information technology. Amman: Safaa Publishing and Distribution House, $1^{\text {rst }}$ Ed. (In Arabic)

Alareeni, B. (2018). Does corporate governance influence earnings management in listed companies in Bahrain Bourse?. Journal of Asia Business Studies, 12(4),551570. https://doi.org/10.1108/JABS-06-2017-0082

Alareeni, B., \& Lulu, M. (2018). The voluntary disclosure of companies listed on Palestine exchange and its effect on stock price. International Journal of Business Ethics and Governance, 1(3), 43-67. https://doi.org/10.51325/ijbeg.v1i3.42 
Al-Faez, S.B.S. (2008). Leadership strategies in managing regulatory change and resistance issues: Case study on the leadership in the Ministry of Interior Affairs in Saudi Arabia [Doctoral dissertation]. (In Arabic)

Al-Haddad, A. B. (2003). Principles of organizational behavior in institutions. Ismailia: Suez Canal University. (In Arabic)

Al-Lami, G. (2007). Technology management concepts and practical technological applications. Amman House for Publishing and Distribution. (In Arabic)

Al-Shanti, M.A.I (2017). The role of transformative leadership in knowledge management operations: A case study of employees of the Palestinian Ministry of Interior in Gaza Strip. Jordanian Journal of Business Administration, 13(3), 440. (In Arabic)

Al-Titi, K.M. (2011). Managerial challenges and strategies for contemporary managers. Amman: Al-Hamid Publishing and Distribution House, $1^{\text {rst }}$ Ed. (In Arabic)

Al-Ziyadat, M.A. (2007). Human resource planning and its role in enhancing competition for a sample of private sector organizations in Jordan. Scientific Journal, 42. (In Arabic)

Atika, B. T. (2013). The impact of the human resource management on the effectiveness of job rewards and competencies: Case study of Algerian banks. Faculty of Economics, Business, and Management Sciences. Second national forum on the management of human resource: Future aspects of human resource management and the scheme to maintain jobs in the Algerian institutions. (In Arabic)

Awdah, A.A. (2013). Human resource management: Effectiveness of administrative work in NGOs-Gaza Strip [Master's thesis]. (In Arabic)

Ben Kirat, S. (2019). The role of knowledge management in improving human resource performance [Master's thesis]. Faculty of Economics, Business and Management Sciences -Department of Economics, Algeria. (In Arabic)

Ben Samaha, A. (2013). The impact of organizational change on innovation in SMEs: Case study of industrial enterprises - Ghardaïa [Master's thesis]. University of Qasdi Marbah, Algeria. (In Arabic)

Chlivickas, E. (2014). International cooperation and innovations for developing human resources system. Procedia-Social and Behavioral Sciences, 110, 276-283. https://doi.org/10.1016/j.sbspro.2013.12.871

Dayan R., Heisig P., \& Matos F. (2017). Knowledge management as a factor for the formulation and implementation of organization strategy. Journal of Knowledge Management, 21(2), 308-329. https://doi.org/10.1108/JKM-02-2016-0068

Findikl1, M. A., Yozgat, U., \& Rofcanin, Y. (2015). Examining organizational innovation and knowledge management capacity the central role of strategic human resources practices (SHRPs). Procedia-Social and Behavioral Sciences, 181, 377-387. https://doi.org/10.1016/j.sbspro.2015.04.900

Gabriel, K. U. (2015). Organizational development, organizational culture, and organizational change. Organizational Culture and Organizational Change (Aug 11, 2015). https://doi.org/10.2139/ssrn.2686104

Giampaoli, D., Ciambotti, M., \& Bontis, N. (2017). Knowledge management, problem solving and performance in top Italian firms. Journal of Knowledge Management, 21(2), 355-375. https://doi.org/10.1108/JKM-03-2016-0113

Hassan A. (2001). Technological development and its effect on human resources in the Egyptian industrial organizations. Journal of Business Research. Faculty of Commerce, Zagazig University, 23. (In Arabic) 
Jadarab, S.M. (2008). Business management references: Modern trends in Health Organization management. Cairo: Al-Ashri Press. (In Arabic)

Jadarab, S.M. (2008). Management systems: Basic and administrative applications. Ismailia, Dar Al Safaa Printing in Mansoura, 346. (In Arabic)

Jadarab, S.M. (2009). Modern trends in business administration. Egyptian Book House,525-526. (In Arabic)

Jadarab, S.M. (2015). Modern trends in crisis management and risk. Egyptian Book House, 177. (In Arabic)

Janjua, S. Y., Khan, M., Naeem, A., \& Kayani, F. N. (2013). Change factors driving management development needs: Empirical evidence from Pakistan. Global Journal of Business Research, 7(2), 83-93. https://doi.org/10.1108/JKM-04-20160163

Junyeong L., Jinyoung M., \& Heeseok L. (2017). Setting a knowledge boundary across teams: Knowledge protection regulation for inter-team coordination and team performance. Journal of Knowledge Management, 21(2), 254-274.

Lendzion, J. P. (2015). Human resources management in the system of organizational knowledge management. Procedia Manufacturing, 3, 674-680. https://doi.org/10.1016/j.promfg.2015.07.303

Mesud, U. (2016). Importance of change and leadership in the $21^{\text {st }}$ century. International Journal of Management Sciences and Business Research, 3(9).

Ministry of Transport, Communications \& Planning. (2017). Report 2016 [Annual report]. Gaza. (In Arabic)

Ministry of Transport, Communications \& Planning. (2018). Report 2017 [Annual report]. Gaza. (In Arabic)

Ministry of Transport, Communications \& Planning. (2019). Report 2018 [Annual report]. Gaza. (In Arabic)

Ministry of Transport, Communications \& Planning. (2020). Report 2019 [Annual report]. Gaza. (In Arabic)

Palestinian Census Report. (2017). [Annual report]. (In Arabic)

Rothberg, H. N., \& Erickson, G. S. (2017). Big data systems: Kknowledge transfer or intelligence insights? Journal of Knowledge Management, 21(1), 92-112. https://doi.org/10.1108/JKM-07-2015-0300

Sumbal, M. S., \& Eric, T.sui, \& Eric, W.K. (2017). Interrelationship between big data and knowledge management: An exploratory study in the oil and gas sector. Journal of Knowledge Management, 21(1). https://doi.org/10.1108/JKM-07-2016$\underline{0262}$

Zamam, N.S.S. (2013). The development of the concept of technology and its application in the educational field. Journal of Humanities and Social Sciences. Mohamed Kheder University in Bascara, Algeria (11). (In Arabic) 